\title{
ASSESSMENT OF BONE MINERAL DENSITY IN FOREARMS OF COLLEGIATE TEN-PIN BOWLERS
}

\author{
A Thesis by \\ Ashley Rose Fryman \\ Bachelor of Arts, Wichita State University, 2008
}

Submitted to the Department of Human Performance Studies and the faculty of the Graduate School of

Wichita State University

in partial fulfillment of

the requirements for the degree of

Master of Education

May 2010 
(C) Copyright 2010 by Ashley Rose Fryman

All Rights Reserved 


\section{ASSESSMENT OF BONE MINERAL DENSITY IN FOREARMS OF COLLEGIATE TEN-PIN BOWLERS}

The following faculty members have examined the final copy of this thesis for form and content, and recommend that it be accepted in partial fulfillment of the requirement for the degree of Master of Education with a major in Exercise Science.

Jeremy Patterson, Committee Chair

Michael Rogers, Committee Member

Mark Vermillion, Committee Member 


\section{ACKNOWLEDGEMENTS}

I would like to thank Dr. Jeremy Patterson for his guidance and dedication through this research, Bryce Winklepleck for his assistance in the data collection, Brett Williams for his assistance in the statistical analysis and Ashley Hervey for her assistance in the data collection, and most importantly her friendship and support as we went through this process together. I would also like to thank the participants of this study for their willing participation in the research. A special thanks to my husband, family and friends for their devoted faith and support in my education and lifee sjourney. 


\begin{abstract}
Studies have demonstrated the effect of dominance on bone mineral density (BMD) of both weight bearing and non-weight bearing limbs and the effect of physical activity and specific sports, such as tennis, gymnastics, and volleyball on bmd of the predominantly used limb(s) versus non-used limb(s). Like tennis and volleyball, the Wichita State University (WSU) bowling team performs a high volume of repetitive use of their bowling arm on a regular basis. This is the first study to investigate the effect of ten-pin bowling at an elite collegiate level on BMD of the bowling arm compared to the non-bowling arm. Dual Energy X-ray Absorptiometry Unit (Hologic QDR 4500W Elite) was used to assess BMD of bilateral arms (whole body scan) and bilateral forearms (forearm scan) of $25(\mathrm{~N}=13$ males, $\mathrm{N}=12$ females) collegiate bowlers $(20.72 \pm 1.46 \mathrm{yrs})$. In this study, the forearm scans showed significantly greater $(\mathrm{p}<0.05)$ BMD in the bowling arm $\left(0.635 \pm .05 \mathrm{~g} \cdot \mathrm{cm}^{-2}\right)$ compared to the non-bowling arm $\left(0.618 \pm .06 \mathrm{~g} \cdot \mathrm{cm}^{-2}\right)$ of both male and female bowlers. However, when separated by gender, the female bowling arm showed a significantly greater difference between arms $(4.1 \pm 3.1 \%$ difference, $\mathrm{p}<0.05)$ and compared to the males $(1.5 \pm 2.6 \%$ difference, $\mathrm{p}<0.05)$. Whole body scans of the left and right arms were also assessed and similar results were observed in the bowling arm compared to the non-bowling arms of males $(3.81 \pm 5.19 \%, \mathrm{p}<0.05)$ and females $(4.15 \pm 2.54 \%, \mathrm{p}<0.05)$. In conclusion, the female elite level collegiate ten-pin bowlers demonstrate an increased BMD in the bowling forearm when compared to the non-bowling forearm.
\end{abstract}




\section{TABLE OF CONTENTS}

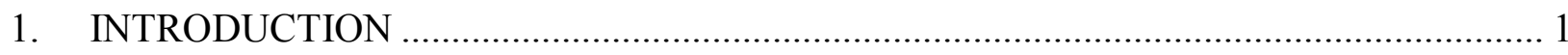

$1.1 \quad$ Statement of the problem ………………………............................................. 3

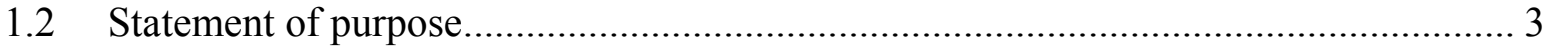

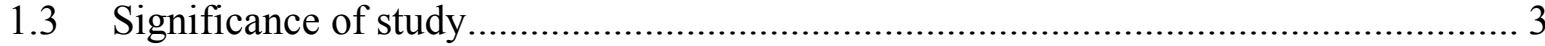

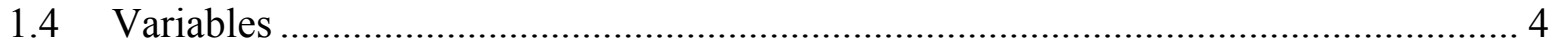

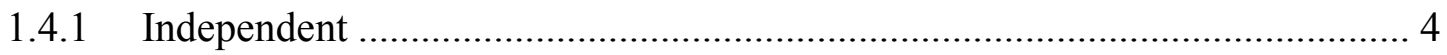

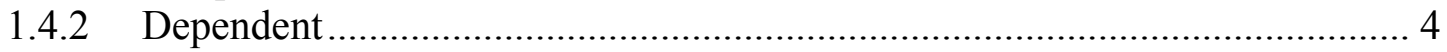

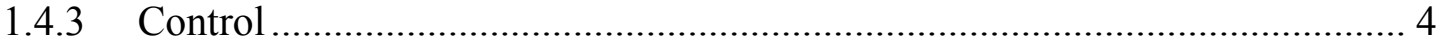

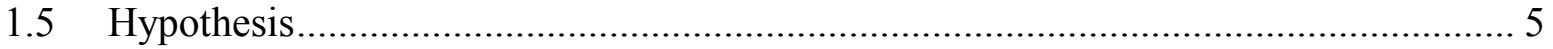

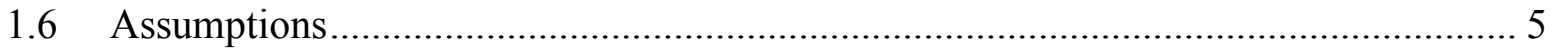

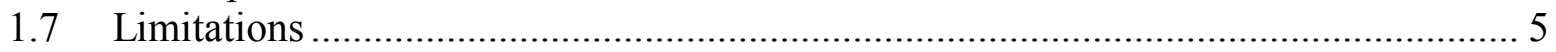

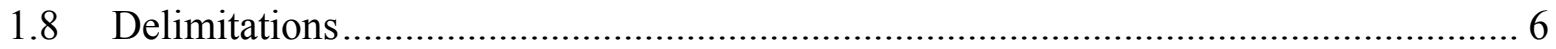

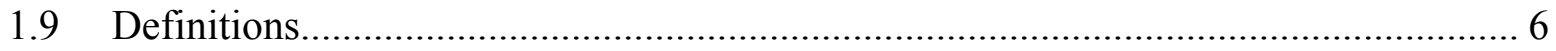

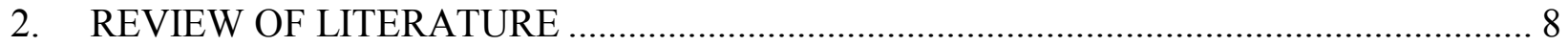

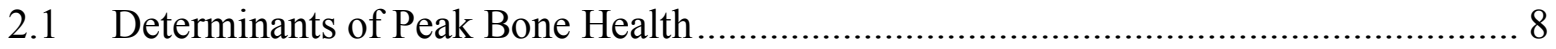

2.1.1 Bone Metabolism............................................................................ 8

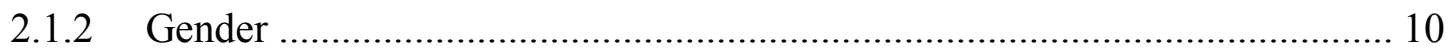

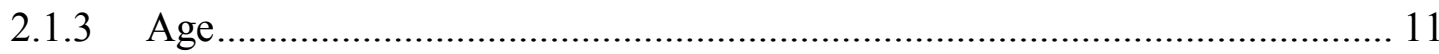

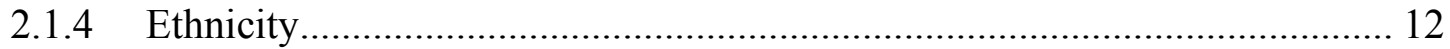

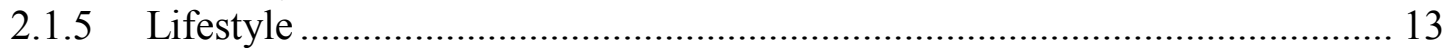

2.1.5.1 Calcium and Vitamin D ............................................................. 13

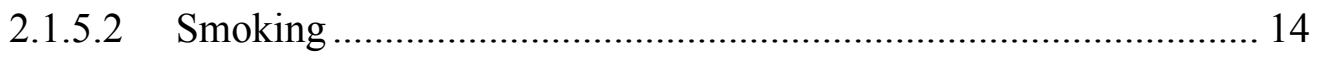

2.1.5.3 Caffeine

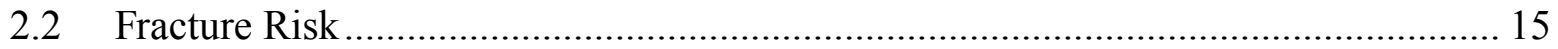

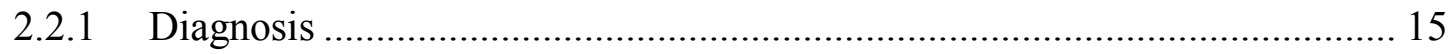

2.2.2 Hip, Vertebral, and Forearm...................................................................... 16

2.3 Influence of Mechanical Loading on Bone Density ……........................................ 17

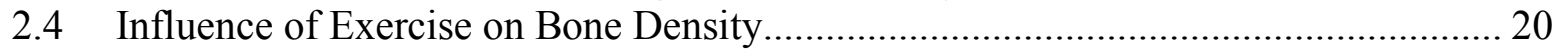

2.4.1 Weight Bearing Exercises...................................................................... 21

2.4.2 Non-weight Bearing Exercises .................................................................. 22

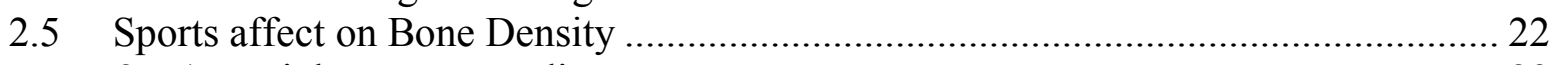

2.5.1 High Impact Loading ………………………........................................ 23

2.5.2 Dynamic/Odd Impact Loading …………………...................................... 26

2.5.3 High Magnitude Loading.......................................................................... 28

2.5.4 Repetitive, Low-Impact Loading ................................................................ 29

2.5.5 Repetitive, Non-Impact Loading ………………….................................. 30

2.6 Forearm BMD …………………………………...................................... 31

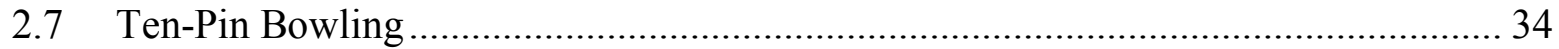




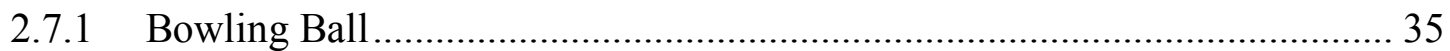

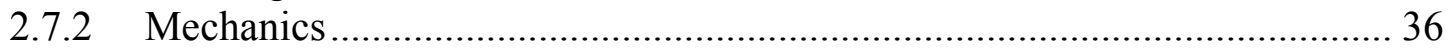

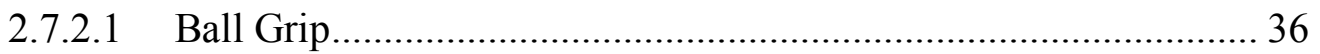

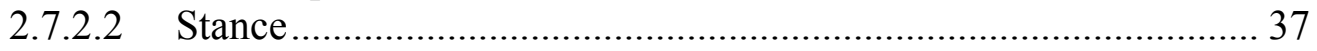

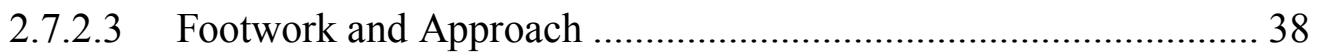

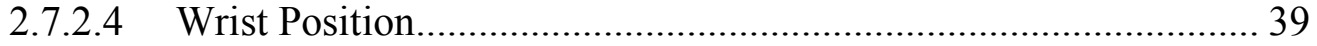

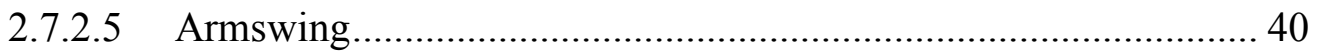

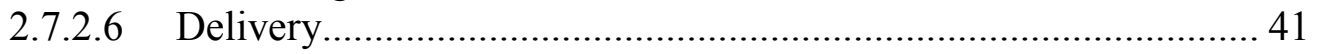

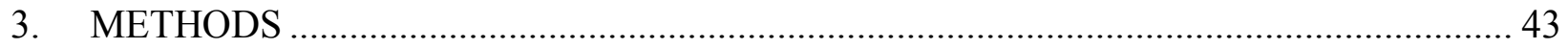

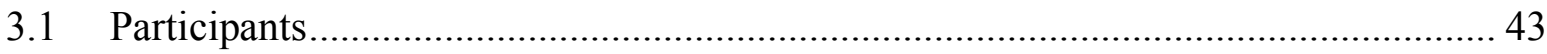

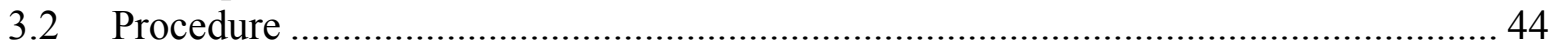

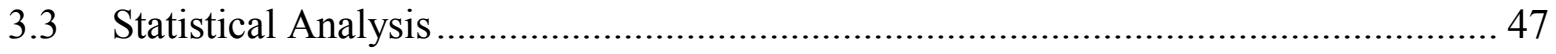

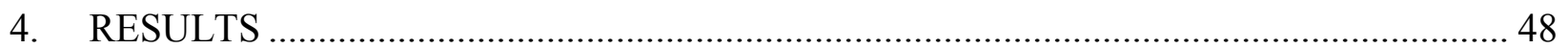

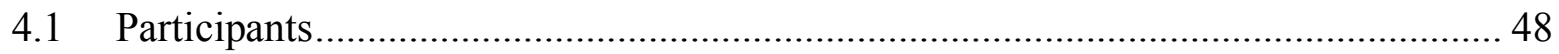

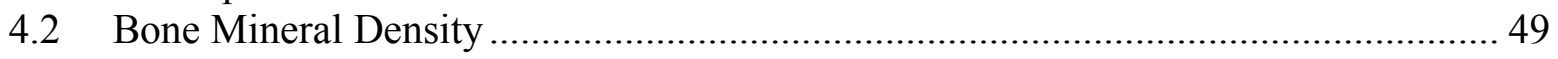

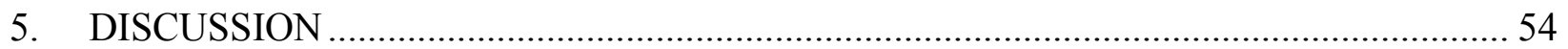

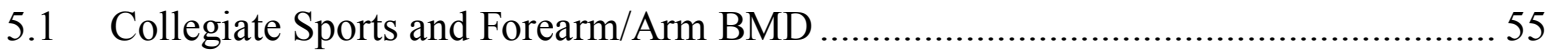

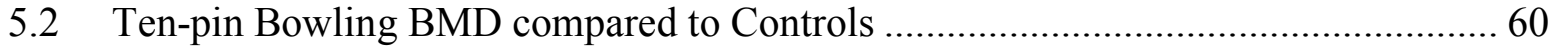

5.3 Ten-pin Bowling BMD Compared to Other Collegiate Sports ..................................... 62

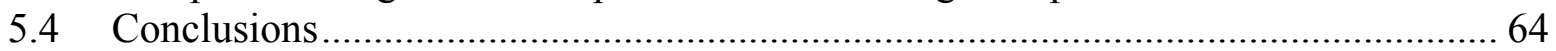

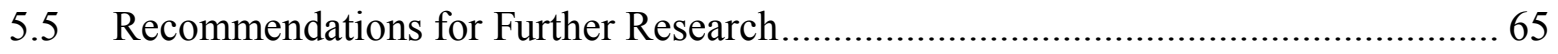

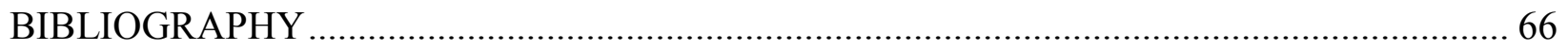

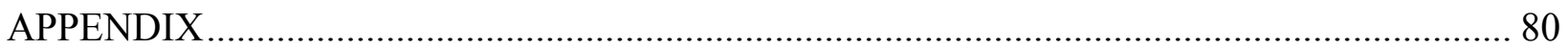

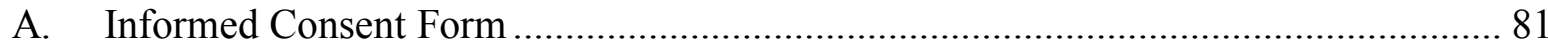

B. Wichita State University Institutional Review Board (IRB) ..................................... 84 


\section{Chapter 1}

\section{INTRODUCTION}

Skeletal tissue naturally regenerates by continuously breaking down and rebuilding bone. The remodeling process can be increased or decreased dependant upon several factors, such as skeletal maturation, an increase in body mass that adds extra ground reaction forces (GRF) on the bones, an increase in weight-bearing activities, diseases that affect bone tissue or from pharmacological interventions (Shepherd \& Lu, 2007). As the body ages, this process begins to slow down. This decrease can also be a result of many other biological processes, such as hormonal imbalances, poor nutrition, and a decrease in physical activity level (Shepherd \& Lu, 2007; Vainionpää et al., 2009). Osteopenia and osteoporosis are major contributors to the increased incidences of fractures seen in post-menopausal women and some older men (Bareither et al., 2008). The effect of osteoporosis also varies between genders (Ali et al., 2009). Approximately 10 million Americans over the age of fifty have osteoporosis, and thirty-four million are at risk of getting osteoporosis (Holroyd et al., 2008).

The World Health Organization (WHO) clinically defines osteoporosis for postmenopausal women as a radial, spinal, or hip bone mineral density (BMD) of 2.5 standard deviations (SD) or more below the mean of healthy, young White women (Bonnick et al., 2010; Sweet et al., 2009). This is expressed as a T-score of -2.5 or below (Bonnick et al., 2010; Holroyd et al., 2008; Mihaljevic et al., 2009; Nichols et al., 2007; Sweet et al., 2009). Dual Energy X-ray Absorptiometry (DXA) units are an accurate, noninvasive method of identifying areal density in individuals of all ages (Bianchi et al., 2010; Carey et al., 2009; Griffith \& Genant, 2008; Holroyd et al., 2008; Leslie et al., 2007; Mihaljevic et al., 2009; Patel et al., 2007). It is currently used as a standard in diagnosis of individuals at risk of osteoporosis, and 
monitoring, preventing and/or treating the disease by providing a gradient of risk that is expressed as a ratio per standard deviation (Leslie et al., 2007; Ozdurak et al., 2003).

The knowledge of osteoporosis and its correlating risk factures aids in the understanding that implementing prevention methods are important. Therefore, educational and prevention methods for prolonging the development of bone issues is needed to begin maximizing bone mass during early adulthood when peak bone mass is reached (Augestad et al., 2004). Physical activity is a significant factor in determining peak bone mass and maintaining bone mass, which are important factors in the prevention of osteoporosis (Iwamoto et al., 2009; Pikkarainen et al., 2009). Activities involving high impact weight-bearing or high peak forces have been shown in many studies to be beneficial and necessary to building greater bone masses, especially in childhood and young adult years (Pikkarainen et al., 2009).

Sports such as gymnasts, rugby, soccer, volleyball, racquet sports, and other athletes who are involved in habitual mechanical loads that generates force on the body, upper and lower extremities supports the many years of research that have shown the benefit of high impact physical activities on bone density (Bareither et al., 2008; Chilibeck et al., 2000). On the contrary, studies have shown that a decrease in physical activity is correlated to an increased reduction of BMD and can result in an increased incidence of osteoporotic fractures (Andreoli et al., 2001; Rautava et al., 2007; Shepherd \& Lu, 2007). Sports that involve dominant use of one limb have shown that the impact of repetitive use in addition to an added force results in side-toside BMD differences between the limbs (Chilibeck et al., 2000). Racquet sports, volleyball, baseball and other throwing athletes have all demonstrated this effect on BMD. Ten-pin bowling is another sport that predominantly uses one arm for bowling with the addition of a weighted bowling ball, but the effect of bowling on BMD has yet to be determined. 


\subsection{Statement of the problem}

Numerous variables influence the BMD of weight-bearing and nonweight-bearing limbs and those variables have been demonstrated extensively in various sports. Ten-pin bowling has been around for a years and is commonly viewed as a leisure or recreational activity. In recent years, bowling has gained more recognition as a sporting event in high schools, college and at professional levels both nationally and internationally. The literature available on ten-pin bowling is relatively limited and there are no known research publications on the subject of tenpin bowling and BMD.

This study seeks to review the knowledge of mechanical loading on BMD of various loads and intensities in sporting activities. The method by which this study seeks to begin is by specifically reviewing research on sports that predominantly involve high intensity and repetitive high volumes of use of the upper extremity limbs and the correlation between those sports and BMD. Then correlate that literature to the sport of ten-pin bowling. No known study has analyzed the effect of bowling on the BMD of the bilateral forearms of elite collegiate ten-pin bowlers.

\subsection{Statement of purpose}

The purpose of this study was to compare BMD of the forearm in elite collegiate ten-pin bowlers to a group of controls not involved in sports or activities that use the upper extremities predominantly.

\subsection{Significance of study}

The game of ten-pin bowling has been around for centuries. During the last fifty years, bowling has gained an increased interest at a professional level and viewed as a competitive sport. Many studies have analyzed the effects of sports on BMD. These include different loading 
mechanisms and involvement of different limbs required in a particular sport. In bowling, the bowler uses their bowling arm repetitively in high volumes on a daily basis. In addition to the high volume of arm movements, a weighted ball is involved, adding a load to the bowling arm. In sports such as tennis and volleyball, these repetitive movements and high impact loads have been shown to be osteogenic on the dominant arm.

To the best of the author"s knowledge, this is the first study assessing the effects of tenpin bowling at an elite collegiate level on BMD of the bowling arm compared to the non-bowling arm. The key piece of this study is the participants. The participants are elite ten-pin bowlers at the collegiate level. Several of the bowlers have also competed on national and world levels. The twenty-five bowlers represent seven different countries, including the USA. Within the USA, eleven states are represented in this bowling team. Therefore, the findings from this study will provide information that is reflective of a broadened demographic view and will have be a greater representation of different cultures and ethnicities for both males and females within the USA and in other countries.

\subsection{Variables}

\subsubsection{Independent}

- Bowling is the independent variable in this study.

\subsubsection{Dependent}

- The dependent variable in this study is the measurements of the bilateral forearms and arms, and total-body BMD assessed by a DXA unit.

\subsubsection{Control}

- The control for this study was participants that were non-bowlers and not currently involved in any sport or activity that required the use of their dominant arm. 
- A control variable in this study is the ages of the participants. All participants were between the ages of eighteen and twenty-four years old.

\subsection{Hypothesis}

The BMD of the bowling forearm and arm will greater than the BMD of the forearm and arm of the non-bowling arm.

\subsection{Assumptions}

It was assumed that the participants followed the pre-scan instructions. In addition, it was assumed that the DXA unit used in this study was in proper working order according to manufacturer policy.

\subsection{Limitations}

The author acknowledges certain limitations of this study associated with experimental design and confounding variables. These limitations are discussed briefly in this section.

- This study did not include collection and analysis of dietary information and serum biomarkers for nutritional status and bone turnover.

- The software available in the WSU Human Performance Laboratory that was used in the DXA measurements analysis did not include references for populations under the age of twenty. Therefore, for subjects under the age of twenty, the software was not able to generate T- and Z-scores.

- The DXA unit used in this study only measures areal bone density, it is unable to distinguish between trabecular and cortical bone tissue. 


\subsection{Delimitations}

This study exclusively selected apparently healthy participants that were between the ages of eighteen and twenty-four years old. By this delimitation, the participants are in the age when peak bone mass is still being obtained.

\subsection{Definitions}

- Bone mineral density (BMD): the adjusted value of hydroxyapatites with respect to measured bone area; measured and calculated commonly with DXA, expressed in units of $\mathrm{g} / \mathrm{cm}^{2}$.

- Bone remodeling: a dynamic, lifelong process of reshaping and replacing bone during growth and after injury (Papachroni et al., 2009).

- Osteoblast: a cell originating from mesenchymal stem cells, responsible for the synthesis of bone matrix (Papachroni et al., 2009)

- Osteoclast: a multinucleated cell, differentiated from hematopoietic monocyte and macrophage precursors, which coordinates resorption of bone (Papachroni et al., 2009)

- Osteocyte: a terminally differentiated osteoblast trapped in its secreted matrix. Osteocytes sense mechanical signals and initiate events of bone remodeling (Papachroni et al., 2009).

- Bone multicellular unit (BMU): a local group of cells with finite lifetime that mediate bone remodeling. Each unit consists of bone-lining cells, osteoblasts, osteocytes, osteoclasts, their precursor cells and their associated cells (endothelial and nerve cells) (Papachroni et al., 2009).

- Mechanotransduction: a three-leg conversion of mechanical cues to electrical or biochemical signals, involving mechanosensing, signal transduction and effector-cell response (Papachroni et al., 2009). 
- Osteopenia: a condition of bone in which there is a generalized reduction in bone mass; however this is less severe than that in osteoporosis (Papachroni et al., 2009).

- Osteoporosis: skeletal abnormality characterized by decreased bone mass owing to the resorption of bone at a rate that exceeds bone synthesis (Papachroni et al., 2009). 


\section{Chapter 2}

\section{REVIEW OF LITERATURE}

\subsection{Determinants of Peak Bone Health}

\subsubsection{Bone Metabolism}

Bone is a dynamic connective tissue that guarantees protection and support of organ function (Proff \& Romer, 2009). The bone tissue is continuously being renewed in a process called bone remodeling, which occurs throughout the human life span to maintain homeostasis and to repair tissue damage that is affecting the quality of bone (Guadalupe-Grau et al., 2009; Karsdal et al., 2006; Mihaljevic et al., 2009; Nichols et al., 2007). Bone tissue is primarily composed of type I collagen, approximately $90 \%$ of total bone protein and the remaining organic component consists of non-structural proteins and inorganic calcium-phosphate mineral (hydroxyapatite) (Pearson \& Lieberman, 2004; Proff \& Romer, 2009; Vicente-Rodriguez et al., 2008). Hydroxyapatite determines tissue stiffness and strength while the organic bone matrix plays a key role on bone toughness (Huang et al., 2010).

Mature bone is composed of two tissue types: cortical (compact) bone and cancellous (trabecular) bone (Flynn, 2003). The cortical bone, is a thick and dense layer of calcified tissue that forms the outer surfaces of most bones and the shafts of long bone, providing the stability of the skeleton (Flynn, 2003). It contains osteons (Haversian systems), which are composed of a central canal (Haversian canal) and surrounded by lamellae of bone matrix (Proff \& Romer, 2009). The lamellae contain the osteocytes, which are embedded in tiny spaces (lacunae) (Proff \& Romer, 2009). Within the Haversian canal there are blood vessels and nerve cells that communicate with the osteocytes (Proff \& Romer, 2009). The outer layer of the cortical bone 
tissue is the periosteum (Proff \& Romer, 2009). The periosteum enables the bone to enlarge because of its inner fibrous layer (Proff \& Romer, 2009).

The inside of the bone is assembled by a cancellous network (spongiosa), ensuring elasticity and stability of the skeleton and accounts for about $70 \%$ of bone metabolism (Proff \& Romer, 2009). Cancellous bone has a spongy appearance and consists of a lattice of thin calcified trabeculae, located at the ends of long bones and within flat bones and the vertebrae body (Flynn, 2003; Griffith \& Genant, 2008).

Bone remodeling is responsible for about $10 \%$ of bone material being renewed each year (Proff \& Romer, 2009). In normal bone, the remodeling process is constant, resulting in a balance between bone resorption and bone formation (Bonnick et al., 2010; Papachroni et al., 2009). At the cellular level, the bone multicellular unit (BMU) contains the two key cell types that are involved in the remodeling process, osteoblasts and osteoclasts (Bonnick et al., 2010; Karsdal et al., 2006; Papachroni et al., 2009; Proff \& Romer, 2009). The synthesizing process of new bone tissue is performed by osteoblasts (Proff \& Romer, 2009). Primarily the osteoblast cells secrete an initial collagen matrix (osteoid) in an organized lattice that creates the basic histological framework of the bone tissue (Pearson \& Lieberman, 2004). The collagen fibers provide the intricate structural framework of bone; it also provides bone with its elasticity and ultimately provides bones with the structural ability to resist tension (Pearson \& Lieberman, 2004).

Osteoclasts are large multi-nucleated cells whose primary function is to resorb bone (Pearson \& Lieberman, 2004). They form a ruffled surface, which attaches to bone surface, creating a seal that is essential for resorption to occur (digestion of collagen) (Pearson \& Lieberman, 2004). Small amounts of bone are permanently lost during the remodeling process 
(Papachroni et al., 2009). At least twenty-four genes that have been identified as having a role in osteoclast function, while any mutation or accelerated osteoclastic activity can produce osteopenia or osteoporosis (Pearson \& Lieberman, 2004). Understanding the relationship between osteoblast and osteoclast activity and the efficient balance of these activities is essential to having a clearer perspective of the relationship between bone structure and bone health. To measure bone turnover, biochemical markers are analyzed in obtained samples of serum or urine (Bonnick et al., 2010).

\subsubsection{Gender}

Bone metabolism has different affects on men and women (Ali et al., 2009). Males tend to have larger bones when compared to females and they tend to have higher peaks of bone mass and greater cortical mass (Ali et al., 2009; Avdagic et al., 2009; Orwoll et al., 2001). The gender differences in peak bone mass attainment are well recognized and may account for a substantial portion of the increased incidence of fragility fractures in women compared to men (Orwoll et al., 2001).

Studies have shown that by the age of seven, the bone mass level in boys is greater than that of age-matched girls by $4.5 \%$ (Zofková, 2008).The gender differences in accrual of bone mass and its qualitative differences are apparent before puberty (Zofková, 2008). Prominent gender differences occur during the stage of early puberty with boys bone density becoming 6$15 \%$ greater than observed girls (Zofková, 2008).

Acceleration rates of bone loss in women during menopause is not equal compared to men (Ali et al., 2009). In the first five years after menopause, women lose bone at a rate of two to three percent per year and then continue to lose about one percent a year after that (Sanders et al., 2009). This loss is an average of one to two percent per year bone mineral loss in cortical 
bone and two to three percent per year in cancellous bone (Flynn, 2003). Around the age of 50, men also begin to lose bone, but at a much slower rate than women (Ozdurak et al., 2003; Sanders et al., 2009). Despite this, around the age of 60 years, the rate of bone loss is about the same for both men and women (Ali et al., 2009; Ozdurak et al., 2003; Sanders et al., 2009).

\subsubsection{Age}

Aging plays an important role on bone cells and subsequently bone mass. Through the aging process, some factors have a stronger impact on bone mineral density (BMD) during a certain period of life, but then have a reduced impact on BMD at other stages of life (Douchi et al., 2004; Nichols et al., 2007). Before adulthood, total bone mass can increase approximately fifty times (Iwamoto et al., 2009). Studies show that age-related changes in bone mass follow the age-related increases in muscle strength, occurring during periods of growth (Lang et al., 2009).

The maximum (peak) bone mass a person obtains occurs during the first two decades of life (Avdagic et al., 2009; Iwamoto et al., 2009). Peak BMD of lumbar spine and of total body is attained between the ages of 18 to 20 years in females and 20 to 23 years in males (Boot et al., 2010). Therefore, accumulation of bone mass during childhood and adolescence is claimed to be the optimal time period for positive skeletal adaptation, when compared to other periods in life (Wilsgaard et al., 2009). During adulthood, a plateau in strength is observed and declines after 30-40 years of age, this age related change is strength is correlated to bone strength (Lang et al., 2009).

For postmenopausal women, the bone turnover process accelerates and as a result the bone integrity deteriorates, doubling the risk of osteoporotic fractures every seven to eight years, after the age of 50 (Bonnick et al., 2010; Iwamoto et al., 2009). By the age of eighty, women on average will have lost approximately $30 \%$ of their peak bone mass (Bonnick et al., 2010). 


\subsubsection{Ethnicity}

Studies have shown there are racial/ethnic differences in BMD of both men and women. African American men exhibit higher BMD than Hispanic or White men (Araujo et al., 2007). In addition, differences between Hispanic and White men are less consistent as observed in the following two studies (Araujo et al., 2007). The Third National Health and Nutrition Examination Survey (NHANES III) indicated that age-adjusted femoral neck BMD in nonHispanic African American and Mexican American men was 12.3\% and 4.6\% higher, respectively, than in non-Hispanic White men (Araujo et al., 2007). Data from the Osteoporotic Fractures in Men Study (MrOS) showed that age-adjusted femoral neck BMD was $11.4 \%$ higher in African American men and $3.2 \%$ lower in Hispanic men compared to White men (Araujo et al., 2007). Lumbar spine BMD was 6.2\% higher in African American men compared to White men (Araujo et al., 2007). There was also no observed difference between Hispanic men and White men (Araujo et al., 2007).

White women have a higher prevalence of osteoporosis and associated fractures (Araujo et al., 2007). It has been observed that African American women have obtained the highest BMD whereas, Asian Americans tend to have the lowest (Bonnick et al., 2010). The age-adjusted lifetime risks of hip fracture in US women are 17\% for White Americans, 14\% for Hispanic Americans, and 6\% for African Americans (Bonnick et al., 2010). However, these differences may be more correlated to body size rather than to race (Bonnick et al., 2010). African Americans and Asians reach their plateau earlier than Whites and Hispanics, demonstrating racial differences in timing of peak BMD, as Whites peak approximately five years earlier than African Americans and Asians (Berenson et al., 2009). 


\subsubsection{Lifestyle}

Environmental factors account for the non-genetic influences on bone health, which includes nutritional intake and lifestyle habits (Rizzoli, 2008). Nutrition, physical activity, and smoking are a few of the numerous life-style factors that are associated with variability in bone density and bone loss (Krall \& Dawson-Hughes, 1993; Wilsgaard et al., 2009). Avoidance of smoking, adequate nutrition and physical activity are advantageous to the safeguarding of bone health (Bonnick, et al., 2010; Wilsgaard, et al., 2009).

\subsubsection{Calcium and Vitamin D}

Nutrition provides the vital components needed for development of normal metabolic functions of bone (Vicente-Rodriguez et al., 2008). Specifically, calcium and vitamin D are perhaps the most important for bone health (Bonnick et al., 2010). Calcium, a mineral, is essential for the structural basis of bones and teeth, and is functional in its storage form (Weaver, 2000). Observational studies on children and adolescents have demonstrated an association between increasing calcium intake and increasing bone mass, which can be correlated to a higher peak bone mass (Rizzoli, 2008).

In North American diets, calcium is generally deficient due to large requirements of calcium that is recommended and the limited availability of concentrated sources of dietary calcium (Bonnick et al., 2010). Dietary sources of calcium are recommended as the primary source because of the other essential nutrients found in high-calcium foods (Bonnick et al., 2010). Dairy products are major contributors to dietary calcium because of their high elemental calcium content, high absorption rate, and relatively low cost (Bonnick et al., 2010). Calcium supplements are also available in a variety of forms to assist in reaching recommended levels of calcium (calcium carbonate and calcium citrate) (Bonnick et al., 2010). Consistent calcium 
supplementation and physical activity appears to be more efficacious in bone development than just exercise or calcium (Vicente-Rodriguez et al., 2008).

Vitamin D, a steroid prohormone, is essential for the physiological regulation and activation of intestinal absorption of calcium and produced in the body through the interaction of sunlight with the skin (Bonnick et al., 2010; Nichols et al., 2007; Sanders et al., 2009). Overall, vitamin D is influential in musculoskeletal health (Bischoff-Ferrari, 2009). There are limited sources of dietary vitamin D. Dietary vitamin D is found in fortified dairy products and fatty fish and supplements (Bonnick et al., 2010). The combination of calcium and vitamin D, have a synergistic effect on bone health in all age groups (Vicente-Rodriguez et al., 2008).

\subsubsection{Smoking}

Smoking has been associated with bone density reduction and accelerated loss (Krall \& Dawson-Hughes, 1993). Smoking can cause loss of thickness in cortical tissue, a decrease in trabecular numbers and thickness and an increase in porosity, which has been observed in mice and is consistent with poor bone health conditions (i.e. low BMD) in humans (Akhter et al., 2005). Long-term exposure to smoking has been correlated to even greater negative effects on bone density (Krall \& Dawson-Hughes, 1993). Female smokers tend to reach menopause two years earlier, on average, inducing bone loss at higher rates than age matched peers (Bonnick et al., 2010). Therefore, smoking creates a significantly higher fracture risk than nonsmokers (Bonnick et al., 2010). The mechanisms response to smoking is not known, but evidence suggests that cigarette smokers have impaired calcium absorption among other factors (Bonnick et al., 2010). 


\subsubsection{Caffeine}

Studies have reported that caffeine has a negative affect on BMD, by negatively influencing calcium absorption, resulting in an increased risk of bone fractures (Zhou et al., 2009). Consumption of caffeinated and uncaffeinated soft drinks over a long period appears to have bone catabolic effects in boys and girls (Libuda et al., 2008).

\subsection{Fracture Risk}

\subsubsection{Diagnosis}

Osteoporosis is a common skeletal disorder that shows characteristics of low bone mineral mass and microarchitectural deterioration of bone tissue, which subsequently increases the fragility of the affected bone, leading to an increased risk of fracture (Bonnick et al., 2010; Holroyd et al., 2008; Jovcevska et al., 2009; Mihaljevic et al., 2009; Ozdurak et al., 2003). Bone strength is a reflection of the integration of bone density and bone quality (Iwamoto et al., 2009). DXA is an accurate, noninvasive method of identifying areal density in individuals of all ages (Bianchi et al., 2010; Carey et al., 2009; Griffith \& Genant, 2008; Holroyd et al., 2008; Leslie et al., 2007; Mihaljevic et al., 2009; Patel et al., 2007). It is currently used as a standard in diagnosis of individuals at risk of osteoporosis, and monitoring, preventing and/or treating the disease by providing a gradient of risk that is expressed as a ratio per standard deviation (Leslie et al., 2007; Ozdurak et al., 2003). BMD measurements of hip, spine, or radius are required for a densitometric diagnosis of osteoporosis (Bonnick et al., 2010).

The most valuable parameter in DXA is T-score, which is defined as the number of standard deviations of BMD from maximum BMD in young adults (Mihaljevic et al., 2009). The World Health Organization (WHO) clinically defines osteoporosis for postmenopausal women, as a spinal or hip bone mineral density of 2.5 standard deviations or more below the 
mean of healthy, young White women (T-score of -2.5 or below) (Bonnick et al., 2010; Holroyd et al., 2008; Mihaljevic et al., 2009; Nichols et al., 2007; Sweet et al., 2009).

A Z-score refers to the number of standard deviations above or below the mean for persons of the same age and gender (Bonnick et al., 2010; Nichols et al., 2007). The International Society of Clinical Densitometry (ISCD) has suggested that the T-score criteria for postmenopausal women not be applicable towards children and premenopausal women because in those populations osteoporosis should not be a diagnosis based solely on BMD measurements (Carey et al., 2009; Nichols et al., 2007). When assessing BMD in men and premenopausal women, Z-scores are more relative in recognizing the presence of „low BMD for age ${ }^{\text {ee }}$ Z-score of -2.0 or less), and the individuals history (Carey et al., 2007; Carey et al., 2009; Nichols et al., 2007).

Clinically, BMD measurements are statistically one of the best predictors of osteoporotic fractures (Douchi et al., 2004; Leslie et al., 2007). A drawback of DXA is its limitation to investigating only planar bone density and analyzing only total BMD at each site (Ahola et al., 2009; Sergi et al., 2009). It is unable to distinguish cortical bone from trabecular, and these two types of bone respond differently to disease, mechanical loading, and aging (Griffith \& Genant, 2008; Sergi et al., 2009).

\subsubsection{Hip, Vertebral, and Forearm}

Approximately ten million Americans over the age of fifty have osteoporosis, and thirty million more are at risk of getting osteoporosis (Holroyd et al., 2008). Estimates suggest that 1.5 million fragility fractures occur each year (Berenson et al., 2009; Holroyd et al., 2008). Most American women younger than fifty have normal BMD, but about 27\% who are osteopenic and $70 \%$ are osteoporotic at the hip, lumbar spine, or forearm by the age of 80 (Holroyd et al., 2008). 
Based on studies performed in North America, the lifetime risk of common fragility fractures is $17.5 \%$ for hip fracture, $15.6 \%$ for clinically diagnosed vertebral fracture, and $16 \%$ for distal forearm fracture for white women around the age of 50 (Holroyd et al., 2008). For age-matched men the corresponding risks are 6\%, 5\%, and 2.5\% (Holroyd et al., 2008).

Hip fractures have a significant impact on an individual ${ }^{\text {ee }}$ s ability to walk. Approximately $40 \%$ of individuals who have experienced a hip fracture are still unable to walk independently one year after the fracture occurred (Holroyd et al., 2008). About 60\% require assistance with one or more essential activities of daily living, such as dressing or bathing (Holroyd et al., 2008). In addition, $80 \%$ are not able to complete one instrumental activity of daily living, such as driving or shopping (Holroyd et al., 2008).

The impact of a single vertebral fracture is relatively low. Fractures of the vertebrae typically result from multiple fractures, which can lead to a progressive loss of height, which is associated with kyphosis and acute and chronic severe back pain (Holroyd et al., 2008). This exacerbates the limited mobility of the underlying osteoporosis, resulting in increased risk of further fractures (Holroyd et al., 2008).

The radius is commonly fractured as a result of a fall, because of the use of the upper extremities in protection against the impact of the fall (Bareither et al., 2008). Fractures to the wrist (distal forearm) do not appear to be as detrimental as hip and spine fractures (Holroyd et al., 2008). A wrist fracture impairs some activities, such as writing or meal preparation, but few become disabled because of the fractured wrist (Holroyd et al., 2008).

\subsection{Influence of Mechanical Loading on Bone Density}

The primary function of bone is to resist deformation in response to both internal and external forces (Guadalupe-Grau et al., 2009; Isaksson et al., 2009; Pearson \& Lieberman, 2004; 
Proff \& Romer, 2009). To efficiently withstand and transmit loads, bone must be inflexible and able to resist deformation (Guadalupe-Grau et al., 2009). On the other hand, if bone is too rigid then it is unable to absorb the energy generated by the shortening and widening of the bone done in response to compression and by lengthening and narrowing when submitted to traction (Guadalupe-Grau et al., 2009). Excessive rigidity of bone is correlated to the structural failure of that bone tissue (Guadalupe-Grau et al., 2009). Many studies focus on the relationship of mechanical loading and BMD by focusing on identifying the threshold and ideal conditions necessary to build and maintain an efficient strong skeletal structure. Several mechanisms have been identified as effective in increasing bone strength. Such methods include, adding bone mass, altering bone geometry, or by changing its microstructure (Andreoli et al., 2001; Kohrt et al., 2004; Pearson \& Lieberman, 2004). Mechanical loading is essential for accrual and maintenance of normal BMC and BMD (Calbet et al., 1999).

Loading on bones occurs in any combination of four ways: being compressed axially, being bent, sheared, or being twisted (Pearson \& Lieberman, 2004). These initiate from forces applied to bone either from the action of a muscle pulling on the bone, external forces acting on a bone across a joint, and/or from gravitational forces (Kohrt et al., 2009; Morel et al., 2001; Pearson \& Lieberman, 2004). Strain characteristics that alter bone metabolism include strain magnitude, the number of strain cycles per second (frequency), and change in magnitude per second (strain rate) (Cullen et al., 2001). Bone has various set points of minimum effective strain (MES) (Bailey \& Brooke-Wavell, 2008; Frost, 1997; 2003). Studies with loading models report that bone formation is linear with an increase in strain magnitude exceeding the relative MES ( 50-100 microstrain) and when the load and frequency are constant, bone formation is frequently increased (Bailey \& Brooke-Wavell, 2008; Cullen et al., 2001; Frost, 1997). Relative 
MES increases as bone adapts to support the greater functional demands that are being placed on it (Bailey \& Brooke-Wavell, 2008).

The mechanical properties in response to loading are affected by intrinsic and extrinsic factors and structural properties (Bailey \& Brooke-Wavell, 2008; Boot et al., 2010; Duncan et al., 2002; Pearson \& Lieberman, 2004). Intrinsic factors include the extent of mineralization and the collection of the tissue (Papachroni et al., 2009; Pearson \& Lieberman, 2004). The response to mechanical loading is known as mechanotransduction or the mechanostat theory. It is the method by which the cells sense mechanical stimuli in their external environment and then interpret the information translating it into a signal that can potentially elicit some response, either within the cell or another cell (Frost, 2003; Lapauw et al., 2009; Papachroni et al., 2009; Pearson \& Lieberman, 2004; Vainionpää et al., 2009). Intracortical fluid flow and the resulting fluid shear stress that result from mechanical loading are the proximal signals that stimulate osteocyte and osteoblast activity (Rector et al., 2009). However, the specific contributions of either mineral content or collagen matrix to the altered bone properties observed after mechanical modulation are not yet known (Isaksson et al., 2009).

If a strain is sufficient enough to be sensed and transduced by bone, bone responds to the mechanical loading by osteogenic cells, which elicit one of the four following potential outcomes (Papachroni et al., 2009; Pearson \& Lieberman, 2004). The first outcome is no response, this could be because the signal was not above the threshold or it was inhibited (Pearson \& Lieberman, 2004). The second possible outcome is that osteoblasts are recruited within the periosteum or endosteum initiating growth of new bone (Pearson \& Lieberman, 2004). Resorption is the third potential outcome when osteoclasts are recruited to resorb bone along a surface (Pearson \& Lieberman, 2004). Finally, the last is bone turnover (Haversian remodeling) 
in cortical bone, occurring as a result of a coordinated and sequential activation of the bone metabolic unit (BMU) (osteoblast and osteoclast activity) (Pearson \& Lieberman, 2004). The BMU are continuously regenerating and have a finite lifetime (Papachroni et al., 2009).

\subsection{Influence of Exercise on Bone Density}

Exercise has been shown extensively to have an advantageous effect on bone mass and geometric adaptations by inducing strains through muscular contractions, which stimulates bone formation (Ahola et al., 2009; Bonnick et al., 2010; Chilibeck et al., 2000; Isaksson et al., 2009; Kohrt et al., 2009; Tervo et al., 2009; Vainionpää et al., 2009). A permanent increase in bone mass does not normally occur in adults, except in instances of periosteal bone formation owing to exercise (Papachroni et al., 2009). Bone cells adapt to habitual loading by changing its structure to be mechanically appropriate according to its loading environment (Ahola et al., 2009; Andreoli et al., 2001). When muscular activity results in specific loading on the skeleton, it responds with enhanced BMD at the specific sites (Bemben et al., 2004). The type, intensity, and duration of the physical activity can affect BMD (Bemben et al., 2004; Maimoun et al., 2006; Vicente-Rodriguez et al., 2008). An exercise program that implements progression allows for continuous overload and stimulation of the bone adaptation process and over long term has an anabolic effect on bone mass and strength (Ahola et al., 2009; Lester et al., 2009).

In contrast, if an exercise program maintains the same loading over a period of time, stimulation of bone formation would only be observed during the first months of training, because bone has the ability to continually adapt to changes in physiological and mechanical environments (Ahola et al., 2009; Guadalupe-Grau et al., 2009). A lack of physical activity causes osteocyte hypoxia and apoptosis, which signals the activation of osteoclasts (Andreoli et al., 2001; Turner, 2000). In the absence of mechanical loading, limbs develop with only $30-50 \%$ 
of normal bone mass (Turner, 2000). Studies on retired athletes found that there is a correlation between low BMD and sedentary lifestyle or reduction in physical activity and more prominent in trabecular bone than cortical bone (Rautava et al., 2007; Tervo et al., 2009).

To sustain BMD obtained from exercise or sport activities, maintenance of mechanical loading training are needed (Rautava et al., 2007). Therefore, the close relationship between muscle mass and BMD insinuates that physical activity plays an important role in skeletal homeostasis (Rautava et al., 2007; Zofková, 2008). The American College of Sports Medicine (ACSM) recommends weight-bearing endurance activities, three to five times per week and resistance exercise two to three times per week to preserve bone health during adulthood (Kohrt et al., 2004).

\subsubsection{Weight Bearing Exercises}

The mechanical loading of growing bones is also site-specific, with the greatest effects in weight-bearing regions of the skeleton (Kohrt et al., 2004; Ozdurak et al., 2003; Turner, 2000). Weight-bearing limbs generate the greatest anabolic response to physical activity and the most severe catabolic response correlated to disuse (Duncan et al., 2002; Kohrt et al., 2004; Turner, 2000). Therefore, weight-bearing exercises directly stimulates bone metabolism and positively influences BMD (Bonnick et al., 2010; Duncan et al., 2002; Ozdurak et al., 2003). Numerous clinical and experimental studies have observed that dynamic loading is more effective than static loading and that high impact-related mechanical strain induces greater osteogenic effects than muscle action alone (Hogstrom et al., 2007; Iwamoto et al., 2009; Maimoun et al., 2006; Pearson \& Lieberman, 2004; Turner, 2000). High impact sports, involving movements of short duration, such as sprinting, hockey, rugby, gymnastics, and volleyball, produce higher BMD (Nichols et al., 2007; Pearson \& Lieberman, 2004). 


\subsubsection{Non-weight Bearing Exercises}

On the contrary, sedentary activities, nonweight-bearing and low-impact exercises are less osteogenic when compared to weight bearing exercises (Bonnick et al., 2010; Iwamoto et al., 2009; Nichols et al., 2007; Pearson \& Lieberman, 2004; Pikkarainen et al., 2009). Swimming, rowing, running, cross-country skiing and cycling are lower-impact endurance sports that typically produce lower BMD compared to high impact sports (Andreoli et al., 2001; Hogstrom et al., 2007; Iwamoto et al., 2009; Nichols et al., 2007; Pearson \& Lieberman, 2004; Turner, 2000). Swimming is performed in a very low-impact environment (water) and provides little osteogenic stimulus that does not significantly increase BMD, even though it is a repetitively strenuous sport (Chilibeck et al., 2000; Duncan et al., 2002; Pearson \& Lieberman, 2004).

\subsection{Sports affect on Bone Density}

The functional adaptation of bone to exercise is associated to the number, magnitude, tare, and distribution of load-induced stresses within the bone (Nikander et al., 2008). Data supporting the importance of mechanical loading derive from numerous studies that analyzed BMD in correlation to different types of sports. Many athletes begin their sports career at a young age. These are the athletes that have shown greater osteogenic effect on bone and attainment of higher peak bone mass (Nichols et al., 2007). The increase in bone mass could be predicted to be positively associated in the reduction of risk for fractures later in life (Nichols et al., 2007). The differences in BMD have consistently been shown between athletes participating in sports involving high GRF and those participating in low- or no-impact sports and are associated with bone health (Bailey \& Brooke-Wavell, 2008; Dowthwaite et al., 2007; Kemmler et al., 2006; Kohrt et al., 2004; Morel et al., 2001; Nichols et al., 2007; Nikander et al., 2005; 
Rector et al., 2009). Total-body BMD is greater in weight bearing sports than in non-weight bearing sports (Morel et al., 2001).

\subsubsection{High Impact Loading}

High-impact activities such as gymnastics, hurdling (jumping) and volleyball augment bone mineral accrual (Bailey \& Brooke-Wavell, 2008; Kohrt et al., 2004; Nichols et al., 2007;

Nikander et al., 2005; Nikander et al., 2008; Pikkarainen et al., 2009; Wilks et al., 2009). Ground reaction force (GRF) during jumping can reach six to eight times body weight and some gymnastic maneuvers generate forces that are ten to eighteen times body weight (Kohrt et al., 2004; Proctor et al., 2002). Both volleyball and hurdling include maximal jumping and leaping, vertically and in forward directions, during a typical sport performance and training (Alfredson et al., 1997; Calbet et al., 1999; Nikander et al., 2005; Nikander et al., 2006).

Volleyball also includes a great number of high-velocity ball impacts onto hands and forearm from various directions (Nikander et al., 2006). This results in the spiking and serving arm being subjected to strains. As a result of these strains and the high-impact nature of the sport, volleyball players show significant differences between BMD and BMC of dominant and 
TABLE 2.1

EFFECT OF SPORTS ON BMD DURING THE PAST FIVE YEARS (BRIEF REVIEW)

\begin{tabular}{|c|c|c|c|c|c|c|c|}
\hline Author & Sport & Exp. & $\begin{array}{l}\text { Mean Age } \\
(\mathrm{yr})\end{array}$ & Cont. & Scan Type & Scans & Results \\
\hline $\begin{array}{l}\text { Dowthwaite, } \\
\text { et al., } 2007\end{array}$ & GYM & $28 \mathrm{~F}$ & 9.5 & $28 \mathrm{~F}$ & $\begin{array}{l}\text { DXA QDR } \\
4500\end{array}$ & DR & $\uparrow \mathrm{BMD}$ UDR \& $1 / 3 \mathrm{DR}$ \\
\hline $\begin{array}{l}\text { Rector, et } \\
\text { al., } 2009\end{array}$ & $\begin{array}{l}\text { WL, RN, } \\
\text { CYC }\end{array}$ & 42 & 30.9 & - & DXA Delphi & $\begin{array}{l}\mathrm{LS}, \mathrm{HP}, \mathrm{A} \\
\quad \mathrm{L}, \mathrm{TB}\end{array}$ & $\begin{array}{c}\mathrm{RT}: \uparrow \mathrm{TB} \& \text { regional BMD vs RN \& } \\
\text { CYC at all site except LS }\end{array}$ \\
\hline $\begin{array}{l}\text { Medelli, et } \\
\text { al., } 2009\end{array}$ & CYC & $23 \mathrm{M}$ & 28.5 & $22 \mathrm{M}$ & DXA Lunar & $\mathrm{TB}, \mathrm{A}, \mathrm{L}$ & MC $\downarrow$ BMD in A vs others \\
\hline $\begin{array}{l}\text { Jürimäe, et } \\
\text { al., } 2006\end{array}$ & RW & $12 \mathrm{M}$ & 20.8 & - & DXA Lunar & $\begin{array}{l}\text { TB, LS, A, } \\
\text { L }\end{array}$ & $\begin{array}{c}\text { Non sig } \uparrow \mathrm{TB}, \mathrm{LS} \& \mathrm{~L} \mathrm{BMD} ; \operatorname{sig} \uparrow \mathrm{A} \\
\mathrm{BMD}\end{array}$ \\
\hline $\begin{array}{l}\text { Kemmler, et } \\
\text { al., } 2006\end{array}$ & $\mathrm{RN}$ & $20 \mathrm{M}$ & 28.5 & $11 \mathrm{M}$ & $\begin{array}{l}\text { DXA QDR } \\
4500 A, Q C T\end{array}$ & $\begin{array}{c}\mathrm{TB}, \mathrm{A}, \mathrm{P}, \mathrm{S} \\
\mathrm{HP}\end{array}$ & $\begin{array}{c}\text { No side-to-side diff., sig } \uparrow \text { P \& LE, sig } \\
\uparrow \text { trabecular in LS, HP }\end{array}$ \\
\hline $\begin{array}{l}\text { Warden, et } \\
\text { al., } 2009\end{array}$ & BA & $15 \mathrm{M}$ & 19.9 & $15 \mathrm{M}$ & DXA, pQCT & $\begin{array}{l}\text { TB, HU, } \\
\text { MR, DR }\end{array}$ & $\begin{array}{l}\uparrow \mathrm{TB}, \mathrm{S}, \mathrm{HP} \text { aBMD, side-to-side diff } \\
\text { in A BMC, no diff in MR or DR }\end{array}$ \\
\hline $\begin{array}{l}\text { Ducher, et } \\
\text { al., } 2005\end{array}$ & $\mathrm{TN}$ & $\begin{array}{l}10 \mathrm{M} \\
10 \mathrm{~F}\end{array}$ & 23 & - & $\begin{array}{l}\text { DXA Delphi, } \\
\text { MRI }\end{array}$ & FA, DR & $\begin{array}{c}\uparrow \text { side-to-side diff in cortical volume in } \\
\text { one-handed backhand players }\end{array}$ \\
\hline $\begin{array}{l}\text { Medelli, et } \\
\text { al, } 2009\end{array}$ & CYC & $73 \mathrm{M}$ & 25.8 & $32 \mathrm{M}$ & DXA Lunar & $\mathrm{TB}$ & $\begin{array}{c}\text { All BMC \& BMD } \downarrow \text { in CYC, } 1 / 3 \text { DR } \\
\text { no sig } \uparrow, \text { no diff. between L, lt A } \uparrow \\
\text { BMC vs rt }\end{array}$ \\
\hline $\begin{array}{l}\text { Pikkarainen, } \\
\text { et al., } 2009\end{array}$ & GYM, RN & $98 \mathrm{~F}$ & 20 & $44 \mathrm{~F}$ & $\begin{array}{l}\text { DXA QDR } \\
\quad 4500 \mathrm{C}\end{array}$ & LS, HP & $\begin{array}{l}\text { 7-yr follow-up: GYM LS \& HP BMC } \\
\text { sig } \uparrow \text { than RN \& cont. }\end{array}$ \\
\hline
\end{tabular}


TABLE 2.1 (continued)

EFFECT OF SPORTS ON BMD DURING THE PAST FIVE YEARS (BRIEF REIVEW)

\begin{tabular}{|c|c|c|c|c|c|c|c|}
\hline Author & Sport & Exp. & $\begin{array}{l}\text { Mean Age } \\
(\mathrm{yr})\end{array}$ & Cont. & Scan Type & Scans & Results \\
\hline $\begin{array}{l}\text { Elloumi, et al., } \\
2009\end{array}$ & $\mathrm{RB}$ & $22 \mathrm{M}$ & 25 & $24 \mathrm{M}$ & $\begin{array}{l}\text { DXA QDR } \\
\quad 4500\end{array}$ & $\begin{array}{l}\text { TB, LS, FE, } \\
\text { HP }\end{array}$ & $\begin{array}{l}\text { Forwards: } \uparrow \text { BMC \& BMD at all } \\
\text { sites no diff between UE BMD }\end{array}$ \\
\hline $\begin{array}{l}\text { Smock, et al., } \\
2009\end{array}$ & $\mathrm{RN}$ & $\begin{array}{l}21 \mathrm{M} \\
28 \mathrm{~F}\end{array}$ & 22 & $\begin{array}{l}17 \mathrm{M} \\
32 \mathrm{~F}\end{array}$ & pQCT & Tibia, FA & $\begin{array}{c}\mathrm{F}: \operatorname{sig} \uparrow \text { bone strength at all sites and } \\
\uparrow \text { vs cont., no diff in } \mathrm{M} \text {. }\end{array}$ \\
\hline $\begin{array}{l}\text { Shaw and } \\
\text { Stock, } 2009\end{array}$ & $\mathrm{CR}, \mathrm{SW}$ & $51 \mathrm{M}$ & 22 & $20 \mathrm{M}$ & pQCT & HU, Ulna & $\begin{array}{c}\text { Ulna rigidity } \uparrow \text { in } \mathrm{CR} \text { than } \mathrm{SW} \& \\
\text { controls }\end{array}$ \\
\hline $\begin{array}{l}\text { Juzwiak, et } \\
\text { al., } 2008\end{array}$ & $\mathrm{TN}$ & $44 \mathrm{M}$ & 15 & $32 \mathrm{M}$ & DXA Lunar & $\begin{array}{c}\mathrm{LS}, \mathrm{HP}, 1 / 3 \\
\text { DR }\end{array}$ & $\begin{array}{c}\text { Sig } \uparrow \text { HP BMD \& dom. FA BMC, } \downarrow \\
\text { BMD non-dom. FA }\end{array}$ \\
\hline $\begin{array}{l}\text { Fredericson, } \\
\text { et al., } 2007\end{array}$ & $\mathrm{SC}, \mathrm{RN}$ & $30 \mathrm{M}$ & 23 & $15 \mathrm{M}$ & $\begin{array}{l}\text { DXA QDR } \\
1000 \mathrm{~W}\end{array}$ & $\begin{array}{l}\text { TB, Tibia, } \\
\text { HP, LS, } \\
\text { calcaneus }\end{array}$ & $\begin{array}{c}\mathrm{SC}: \operatorname{sig} \uparrow \mathrm{BMD} \text { at all sites vs cont } \& \\
\text { sig } \uparrow \mathrm{rt} \text { HP \& S BMD vs RN }\end{array}$ \\
\hline $\begin{array}{l}\text { Mudd, et al., } \\
2007\end{array}$ & $\begin{array}{l}\text { GYM, SB, } \\
\text { CC, TR, } \\
\text { FH, SC, } \\
\text { RW, SW, } \\
\quad \text { RN }\end{array}$ & $99 \mathrm{~F}$ & 20.2 & - & $\begin{array}{l}\text { DXA QDR } \\
1000 \mathrm{~W}\end{array}$ & TB, LS, P, L & $\begin{array}{c}\text { RN lowest TB \& site specific BMD } \\
\text { except L compared to GYM \& SB; SW } \\
\text { sig } \downarrow \text { L BMD than all sports except RN } \\
\& \text { RW }\end{array}$ \\
\hline \multicolumn{8}{|c|}{$\begin{array}{l}\text { Abbreviations: Exp (experimental group), Cont (control group), TB (total body), LS (lumbar spine), A (arm), L (leg), HP (hip), FE } \\
\text { (femur), FA (forearm), DR (distal radius), UDR (ultra distal radius), 1/3 DR (1/3 ultra distal radius), MR (midshaft radius), P (pelvis), } \\
\text { S (spine), LE (lower extremity), UE (upper extremity), HU (humerus), F (female), M (male), MC (mountain climbers), RB (rugby), } \\
\text { SC (soccer), GYM (gymnastics), WL (weight lifting), RN (running), CYC (cycling), RW (rowing), BA (baseball), TN (tennis), CR } \\
\text { (cricket), SW (swimming); SB (softball); TR (track); FH (field hockey) }\end{array}$} \\
\hline
\end{tabular}


contralateral arms (forearm and proximal and distal humerus) and legs (Alfredson et al., 1998; Calbet et al., 1999). Volleyball players have higher total body BMD values than the nonactive individuals (Alfredson et al., 1997). In addition, BMD of the spine was significantly higher (Alfredson et al., 1997). The BMD of the proximal femur is also greater in the dominant leg compared to the nondominant leg (Alfredson et al., 1997). In comparison of volleyball to racquet sports, racquets sports BMD side-to-side difference is typically greater than that of volleyball players (Alfredson et al., 1998).

Gymnastics is a unique sport in the manner that the upper limbs are involved in both weight bearing and high-impact loading forces typically experienced in the lower extremities (Proctor et al., 2002). The impact loading is approximately four to twelve times body weight (Bailey \& Brooke-Wavell, 2008; Nichols et al., 2007). In one study, the BMC measured at the lumbar spine and femoral neck was significantly higher in gymnasts compared to runner and control groups during baseline (career peak) measurements and over a seven year follow-up (Pikkarainen et al., 2009). In another study on Danish female elite gymnasts (artistic and rhythmic), the BMD was significantly higher then BMD in the controls (Helge \& Kanstrup, 2002). In female collegiate gymnasts, similar results of significantly higher BMD and BMC in total-body, lumbar spine, femur, and upper-limbs compared to age-matched were found (Proctor et al., 2002).

\subsubsection{Dynamic/Odd Impact Loading}

Soccer, baseball, racquet sports (tennis and squash), and rugby are sports that are intensive in nature and involve intermittent and high-intensity activities that include sprinting, jumping, accelerating (Fredericson et al., 2007; Nikander et al., 2005). In addition to these movements, transverse and torsional loads are also involved in these sports, generated by the fast 
changes in body direction (Fredericson et al., 2007). These are dynamic or odd impact loading sports. Soccer also involves kicking and receiving the ball, which can result in impacts to the foot and shin. Dynamic loading of soccer on the femur during practice or a game can often exceed five times body weight (Frost, 2003). Soccer is associated with higher BMD of all commonly measured skeletal sites compared to controls and runners (Fredericson et al., 2007).

Throwing athletes (baseball players, cricketers, and discus) are an alternative population used to study skeletal effects of mechanical loading and are similar to racquet sports in the manner that throwers overload their dominant upper extremity (Shaw \& Stock, 2009; Warden et al., 2009; Whittington et al., 2009). The difference between throwers and racquet sports is that the upper extremity loading is entirely generated via internal forces (Warden et al., 2009). Whole arm and midshaft BMC are eight and one-half percent higher in the dominant upper extremity in baseball players compared to controls (Warden et al., 2009). Regional areas (hip, spine and nondominant upper extremity) BMD was also superior to controls (Warden et al., 2009). Bone adaptation of the upper extremity related to throwing is localized to the humerus, no effect of throwing is found on the radius (Warden et al., 2009). For the humerus, the playing position plays another factor on accrual of BMD. Pitchers and catchers display greater dominant-to-nondominant differences than fielders (Warden et al., 2009). Compared with controls, cricketers dominant humerus and ulna are significantly stronger in resistance to torsional deformation (Joules), increasing bone rigidity (Shaw \& Stock, 2009). Pronounced asymmetries are also observed in these skeletal areas (Shaw \& Stock, 2009).

Tennis and squash, similarly to volleyball, include a large number of high-velocity ball impacts onto the racquet from different directions (Nikander et al., 2006). The racquet increases the lever arm, which magnifies the incident of joint moment within the upper extremities 
(Nikander et al., 2006). Handball activities are associated with higher axial and appendicular BMD and BMC (Ducher et al., 2004; Sanchis-Moysi et al., 2004; Vicente-Rodriguez et al., 2004). Differences exist between dominant and contralateral arm in BMD and BMC and minor asymmetries observed in lower extremity, only BMD was higher in contralateral leg (Juzwiak et al., 2008; Sanchis-Moysi et al., 2004; Vicente-Rodriguez et al., 2004). Long-term tennis players display greater bone mass at the dominant distal radius, which is associated with an increase in bone size and slight improvement in volumetric BMD (Ducher et al., 2005; Ducher et al., 2006).

\subsubsection{High Magnitude Loading}

Football and rugby account for most activity time in subjects that participate in highimpact activities because these two sports are often played at young ages and continued throughout the school years (Ginty et al., 2005). Rugby is a sport that involves weight bearing, dynamic loading and applies high magnitude strains on the skeleton. There are studies that have reported an increased $\mathrm{BMD}$ and $\mathrm{BMC}$ in male rugby players than those observed in controls in all measured areas of the skeleton (total-body, upper limbs, spine, lumbar spine, pelvis, lower limbs, femur, and femoral neck) (Elloumi et al., 2009; Morel et al., 2001; Nevill et al., 2004). This is more prominent in forwards, who are frequently engaged in physical contact that involves the use of the arms, legs, pelvis, and spine (Elloumi et al., 2009; Morel et al., 2001).

The most commonly recognized high magnitude loading activity on the skeleton is weightlifting. Weightlifting involves well-coordinated movement with simultaneous, very high muscle force production, therefore representing high magnitude loading (Nikander et al., 2005). Frequently, weightlifting is a supplementation component in various sports workout regimens to enhance performance. Weightlifting (bodybuilding) is also a sport of its own. Intensive weightlifting exercises have significant influences on increasing bone mass of the upper limbs 
than non-weightlifting exercises (Hamdy et al., 1994; Nevill et al., 2004; Nikander et al., 2005). BMD of the spine is also significantly higher in professional weightlifters (Morel et al., 2001).

\subsubsection{Repetitive, Low-Impact Loading}

Endurance running (marathons), cross-country skiing and rowing are endurance sport which includes a large number of similar weight-bearing impacts against ground and represent repetitive, low-impact loading (Nikander et al., 2005; Pettersson et al., 2000). During each foot strike, running applies loads to the bone from the weight of the body contacting the ground and from the pull of a local contracting muscle (Smock et al., 2009). GRF produced in the lower limbs during running or walking is one to five times body weight, which has been reported to be enough to initiate bone adaptation (Bailey \& Brooke-Wavell, 2008; Kohrt et al., 2004; Morel et al., 2001; Smock et al., 2009).

$\mathrm{BMD}$ of male and female long distance runners who run more than forty miles per week have been observed to be lower than that of other athletes (Kerschan-Schindl et al., 2009; Matsumoto et al., 1997). BMC of the spine in male elite runners running more than sixty-two miles per week has been shown to be nineteen percent lower while the bone turnover variables were twenty to thirty percent higher than non-running controls (Kerschan-Schindl et al., 2009). In highly trained female runners studies report three to twenty-four percent lower BMD compared to age-matched controls (Kerschan-Schindl et al., 2009). In a study of female and male collegiate runners, the females had substantially greater (17-19\%) estimates of tibia bone strength than controls at both the distal and midshaft sites and moderately greater (11\%) bone strength at the radius midshaft (Smock et al., 2009). However, no observed differences in bone strength for the male runners compared to the controls, but some differences in cortical bone geometry (Smock et al., 2009). Therefore, runners may have a threshold between forty-nine and 
sixty-two miles a week, below which the effects on bone appear to be positive and running beyond the threshold may be harmful to bone metabolism (Kerschan-Schindl et al., 2009).

Cross-country skiers normally train and compete with two different techniques of skiing (original diagonal stride and skating styles) (Pettersson et al., 2000). The distribution between these two techniques is about half of each during the skiers" training and competition (Pettersson et al., 2000). A lot of arm work is also involved during uphill skiing, GRF in the pole can reach values equivalent to fifty percent of the body weight during the diagonal strike (Pettersson et al., 2000). As a result of these mechanics, BMD of cross-country skiers is higher at the right and left whole humerus, femoral neck and greater trochanter than in the controls (Pettersson et al., 2000). The side-to-side differences in BMD of the whole humeri is significant in control groups, but not evident in cross-country skiers (Pettersson et al., 2000). In highly trained rowers, BMD and $\mathrm{BMC}$ are higher compared to the respective measurements in different endurance athletes such as novice rowers, cyclists and swimmers, but is similar to finding in runners (Jurimae et al., 2006; Nichols et al., 2007).

\subsubsection{Repetitive, Non-Impact Loading}

Repetitive, non-impact loading sports have not been associated with any significant benefit in any bone value (MedelliShabani et al., 2009; Nikander et al., 2005). Cycling and swimming are endurance sports that involve a great number of movements but lack all the ground impacts (Nikander et al., 2005; Nikander et al., 2006). The loading impact in these two sports is zero or near zero time body mass (Bailey \& Brooke-Wavell, 2008; Nichols et al., 2007).

In swimming, there are substantial drags of water against the movements of the arms and legs, generated by repeated concentric contractions (Duncan et al., 2002; Nikander et al., 2006). 
To support these movements swimmers include functional weightlifting in their training focusing primarily on concentric muscle work (Nikander et al., 2006). One study showed that swimming had nonsignificant different arm BMD and lowest BMD of the groups studied (Duncan et al., 2002). The muscle tensile forces produced in swimming is not enough to stimulate bone turnover and is considered one of the least osteogenic sports (Duncan et al., 2002). Similar findings have been demonstrated in studies of rats (Huang et al., 2010).

Cycling is a popular sport and the oldest sport in machine-aided locomotion. Studies have suggested that both young elite and master road cyclists have lower or comparable spine, hip, or femoral neck BMD compared with controls even when the amount of daily calcium intake appears adequate (MedelliShabani et al., 2009; Wilks et al., 2009). In relation to the mechanostat theory, cycling should act as an osteogenic stimulus, particularly at faster speed (Wilks et al., 2009). One study found measures of the tibia and radius to be average or above average compared to controls (Wilks et al., 2009). A recent study on professional cyclists, found that two-thirds of the professional cycling team had abnormally low BMD values (MedelliLounana et al., 2009). This leads to a concern of the increased risk of osteoporotic bone.

\subsection{Forearm BMD}

The mid-radius contains greater than ninety-five percent cortical bone, whereas the distal forearm BMD measurement represents mostly cancellous bone and it is more metabolically active than cortical bone (Ginty et al., 2005; Holmberg et al., 2004; Sergi et al., 2009). The ultradistal radius has a greater proportion of trabecular bone (Ginty et al., 2005). The distal radius would be one of the first sites of the forearm where bone loss is detectable (Holmberg et al., 2004). Most fractures preferentially affect the distal radial metaphysis. This is because of the adaptation to uniaxial compression of typical peak voluntary mechanical loading (TPVML) 
resulting from the low friction of the wrist joint as this protects the metaphysis from large shearing, bending, and torsional loads (Frost, 2003). Despite this the radial diaphysis normally adapts to repeated combined uniaxial, bending, and torsional TPVMLs from arm and forearm muscles (Frost, 2003).

With this information, strength training activities and weight-bearing exercises are known to produce positive effects on BMD (McClanahan et al., 2002). The mechanical loading of specificity training correlated with greater BMD affects the specific regions in response to the particular type of exercise (Andreoli et al., 2001; McClanahan et al., 2002; Ozdurak et al., 2003). The upper extremities lack the regular weight-bearing component, which leads to the role of muscle performance that modulates the skeletal response to incident loading (Nikander et al., 2006). In the upper extremities, strongest bone structures among athletes whose sports involve high-magnitude loading, such as weightlifting, or high impact loading, such as tennis (Nikander et al., 2006; Proctor et al., 2002). Individuals involved in weightlifting activities, either as the primary exercise program or as a part of a combined exercise program had higher BMD of upper limb bones than those who participated in nonweight-lifting activities (Hamdy et al., 1994).

BMD is higher in dominant versus non-dominant limbs (Akar et al., 2002; Chilibeck et al., 2000; Proctor et al., 2002). Significant differences in bone density and structure between dominant and non-dominant limb are attributed to lifetime loading of the favored dominant side (Bailey \& Brooke-Wavell, 2008). The knowledge of the effect of limb dominance is important in order to be able to investigate bone and muscle changes resulting from activities that predominantly uses the dominant arm (Chilibeck et al., 2000; Rector et al., 2009; Sergi et al., 2009). Cross-sectional comparing contralateral limbs of athletes and nonathletes have observed higher BMD in the dominant forearm in the athletes, especially at site of trabecular bone tissue 
(Duncan et al., 2002; McClanahan et al., 2002; Proctor et al., 2002; Sergi et al., 2009; Walters et al., 1998). Another study observed cortical bone tissue to be greater in the dominant arm compared to the non-dominant arm (Rico et al., 1994).

Several studies have supported these site-specific adaptations in athletes (McClanahan et al., 2002). In both men and women, side-to-side differences in BMD have been observed in athletes participating in sports that rely on the use of the dominant arm to execute necessary moves during practice and game (McClanahan et al., 2002; Morel et al., 2001). Tennis and squash players have greater bone mass in their playing arm compared to their non-playing arm (Akar et al., 2002; Chilibeck et al., 2000). In volleyball players, the arm used for spiking has a greater bone mass than their non-spiking arm (Akar et al., 2002; Chilibeck et al., 2000). BMD data from gymnasts have also demonstrated that the dominant upper limb is significantly greater than the nondominant and controls (Proctor et al., 2002). The athletes who started their sporting careers as children have a two- to four-fold greater difference in BMD between playing arm and nonplaying arm, compared with those who began playing as young adults (Karlsson, 2004; Turner, 2000).

For nonathletes, the difference between the dominant and nondominant arm is smaller, but significant, implicating that repetitive everyday use provides a greater stimulus for building bone mass (Chilibeck et al., 2000). Some studies have reported that gender differences do not have an effect on distal forearm BMD asymmetry (Akar et al., 2002; Capozza et al., 2004). In studies of bilateral differences in arm BMC of national level male tennis player (13-25\%) were significantly greater than in controls $(1-5 \%)$ and this difference persisted four years after retirement (Kohrt et al., 2004). 
TABLE 2.2

EFFECT OF DOMINANCE ON FOREARM AND ARM BMD IN NON-ATHLETES

\begin{tabular}{|c|c|c|c|c|c|c|}
\hline Author & Exp. & $\begin{array}{c}\text { Mean } \\
\text { Age (yr) }\end{array}$ & Cont. & $\begin{array}{l}\text { Scan } \\
\text { Type }\end{array}$ & Scans & Results \\
\hline $\begin{array}{l}\text { Akar, et al., } \\
\quad 2002\end{array}$ & $\begin{array}{l}19 \mathrm{M} \\
18 \mathrm{~F}\end{array}$ & 21 & - & $\begin{array}{l}\text { DXA } \\
\text { QDR } \\
4500 W\end{array}$ & $\begin{array}{l}\text { Bilateral } \\
\text { FA }\end{array}$ & $\begin{array}{c}\text { Distal FA sig } \uparrow \text { in rt FA vs } \\
\text { lt FA BMC, BMD sig } \uparrow \\
\text { between rt \& lf at mid FA }\end{array}$ \\
\hline $\begin{array}{l}\text { Özdurak, et } \\
\text { al., } 2003\end{array}$ & $46 \mathrm{M}$ & 56.7 & $45 \mathrm{M}$ & $\begin{array}{l}\text { DXA } \\
\text { Lunar- } \\
\text { DXP }\end{array}$ & $\begin{array}{l}\text { Bilateral } \\
\text { FA }\end{array}$ & $\begin{array}{l}\text { No sig diff between dom } \\
\& \text { non-dom forearm BMD }\end{array}$ \\
\hline $\begin{array}{l}\text { Chilibeck, et } \\
\text { al., } 2000\end{array}$ & $\begin{array}{c}53 \\
\text { PMF }\end{array}$ & $\begin{array}{c}20.9 \& \\
57.4\end{array}$ & $25 \mathrm{YF}$ & $\begin{array}{l}\text { DXA } \\
\text { QDR } \\
1000\end{array}$ & $\begin{array}{l}\text { Bilateral } \\
\text { A }\end{array}$ & $\begin{array}{l}\text { Sig } \uparrow \text { BMD \& BMC in } \\
\text { dom A vs non-dom A }\end{array}$ \\
\hline $\begin{array}{l}\text { Rico, et al., } \\
1994\end{array}$ & $\begin{array}{l}20 \mathrm{M} \\
30 \mathrm{~F}\end{array}$ & 26 & - & $\begin{array}{c}\mathrm{pQCT} \\
\text { XCT } 900\end{array}$ & $\mathrm{FA}, \mathrm{A}$ & $\begin{array}{l}\text { Total and cortical BMD } \\
\text { sig } \uparrow \text { in dom A, no diff in } \\
\text { trabecular BMD }\end{array}$ \\
\hline $\begin{array}{l}\text { Sergi, et al., } \\
\quad 2009\end{array}$ & $\begin{array}{l}30 \mathrm{M} \\
30 \mathrm{~F}\end{array}$ & 39 & - & $\begin{array}{l}\text { pQCT } \\
\text { XCT- } \\
3000\end{array}$ & $\begin{array}{l}\text { Proximal } \\
\text { \& DR }\end{array}$ & $\begin{array}{l}\text { No sig diff in BMD } \\
\text { between dom \& non-dom } \\
\text { FA at any site for M or F }\end{array}$ \\
\hline $\begin{array}{l}\text { Walters, et } \\
\text { al., } 1998\end{array}$ & $213 \mathrm{~F}$ & - & - & $\begin{array}{l}\text { DXA } \\
\text { QDR } \\
1000 \mathrm{~W}\end{array}$ & FA, Hip & $\begin{array}{c}\text { Dom FA sig } \uparrow \text { bone area and } \\
\text { BMC; BMD sig } \uparrow \text { only in } \\
\text { ulna of dom FA }\end{array}$ \\
\hline $\begin{array}{l}\text { Abbreviatio } \\
\text { (significant) }\end{array}$ & $\mathrm{M}(\mathrm{m}$ & $\begin{array}{l}\text { F (fema } \\
\text { left); dc }\end{array}$ & A ( & $\begin{array}{l}\mathrm{rm}) ; \mathrm{A}(\mathrm{c} \\
\text {; non-do }\end{array}$ & הוד & $\begin{array}{l}\text { al radius); sig } \\
\text { lant) }\end{array}$ \\
\hline
\end{tabular}

\subsection{Ten-Pin Bowling}

The game of bowling has roots that trace back to 3200 BC in Egypt, but the first written reference to bowling was in 1366, when King Edward III of England banned his troops from playing the game so that they would not be distracted (TenpinBowling.org, 2003-2006). Bowling was primarily a sport for the upper class during that time. Modern American ten-pin bowling is similar to the German ninepin game and was a sport of the working class until the period of 1940 to 1960 when it gained popularity and advances in its game (TenpinBowling.org, 2003-2006). 
Bowling is a game that today is played by people of all ages. More recently, a new introduction to the sport of bowling has evolved through an interactive video game that is used by the young and the old. Bowling can also be played occasionally as an event for a birthday party or time spent with friends and family, this is referred to as open bowling. Another level of bowling is recreational playing, which includes bowling on a regular basis in events such as long and short season league play. Then there are the more competitive levels and the professional levels of the sport of bowling that involves minor and major world tournaments (TenpinBowling.org, 2003-2006). Middle school and high school is typically the starting age of competing in higher levels of bowling. During the college years, this continues as the bowler becomes more involved in larger tournaments.

There are national regulatory organizations that govern the sport"s rules and conduct, and many of those countries ${ }^{\text {ee }}$ best players participate in tournaments on both national and international stages (TenpinBowling.org, 2003-2006). There are many aspects to the game of bowling that are important to consider, this includes choosing the appropriate bowling ball and understanding the proper mechanics in order to enhance performance.

\subsubsection{Bowling Ball}

Obtaining an optimal bowling ball for the bowler is an important component for ultimate performance. A bowling ball should be the proper weight and proper quality for it to be a good fit for the bowling individual in order to maintain fluid body movement and fundamental mechanics (Mullen, 2004; United States Bowling Congress, 2006; 2008). If the ball is too light, it can be overpowered by the arm, which inhibits the pendulum effect of bowling mechanics (Mullen, 2004). On the contrary, if the ball is too heavy, then it is difficult to develop a full and loose arm swing (Mullen, 2004). 
There are a couple of methods available to help an athlete determine the appropriate ball weight. One method is to place the palm of the bowling hand with the hand supinated with the elbow adjacent to the torso in a ninety-degree flexed position so that the forearm is parallel to the ground (United States Bowling Congress, 2006). The appropriate ball weight will seem slightly heavy to the bowler resulting in the bowling hand to be pushed downward a little but is able to maintain the hand and forearm at the ninety-degree position (United States Bowling Congress, 2006). Another method is to utilize a piece of cloth that has two handles used to carry a ball, "ball sling". The bowler would place a ball in the sling and swing it back and forth. When the ball is the appropriate weight for the bowler, then the athlete is not able to readily change the direction of the armswing but does not force the body to tense up (United States Bowling Congress, 2006). The weight of the ball should not exceed sixteen pounds (TenpinBowling.org, 2003-2006).

The covering of the ball is as important as determining the appropriate ball weight. It determines the amount of friction the ball will create on the lane, this is important for throwing a hook (ball spins in a counterclockwise direction (Mullen, 2004). Plastic balls create little friction with the lane (Mullen, 2004). Most performance balls have urethane covers (contains reactive resin) that allows the ball to create more friction on the lane and hits the pins better than plastic balls (Mullen, 2004).

\subsubsection{Mechanics}

\subsubsection{Ball Grip}

There are two types of grips commonly used in bowling, the conventional grip and the fingertip grip. The conventional grip is used primarily in the beginners (Mullen, 2004). The ball that is designed for the conventional grip has the finger holes located closer to the thumb and is 
larger in diameter to fit the fingers up to the second joint and the thumb is able to slide into the hole up to the base of the thumb (Mullen, 2004). The fingertip grip is preferred by the more experienced bowlers (Mullen, 2004). With this grip, the fingers go into the holes up to the first finger joint and the holes are spaced further from the thumb (Mullen, 2004). An advantage of this technique is that it allows for more ball revolutions and hits the pin better (Mullen, 2004).

When using the proper ball, the holes in the ball should fit the fingers and thumb of the bowler so that the ball can remain in the hand with the palm lying across the ball so that the grip tension is not too much or too little (squeezing or clenching the ball is not necessary) (Mullen, 2004). The pressure should be maintained throughout the swing phase and during the release the thumb leaves the ball before the fingers (this applies to both ball grips) (Mullen, 2004).

\subsubsection{Stance}

In the bowling stance, the feet start in a staggered position so that the toes on the ballside foot are adjacent to the instep of the non-ball side foot. The spine tilts forward fifteen degrees, placing the upper body directly over the individuals center of gravity, and the bowler"s body weight is evenly distributed between both legs with the knees slightly bent (Mullen, 2004; United States Bowling Congress, 2006). While in the stance position the body should be in a comfortable and relaxed state, anticipating the next movement (Mullen, 2004; United States Bowling Congress, 2006).

The hand holding the ball, is placed underneath or slightly to the side of the ball (comfort is dependent on the individual) and the opposite hand supports most of the weight of the ball to allow the swing arm to remain relaxed (Mullen, 2004). The elbow of the swing arm should be by the side, adjacent to the ribs and held in line with the shoulder with the shoulder lined up with the appropriate target to hit the pocket (Mullen, 2004; United States Bowling Congress, 2006). This 
position allows the armswing to move freely along the side of the body throughout the entire approach and delivery (United States Bowling Congress, 2006).

\subsubsection{Footwork and Approach}

There are a few different approach techniques that bowlers can use that best suits the bowler. For the first technique, the one-step approach the bowler must first determine the starting position. The bowler does this by starting at the foul line with the individual "s seels on the dots and then takes one and one-half steps away from the foul line while looking straight ahead to reduce the tendency of lengthening the stride and then pivot to face the lanes (United States Bowling Congress, 2006; 2008). Beginning with the bowling stance, as the arm moves forward in the swing the non-ball side starts to slide forward (United States Bowling Congress, 2006). The knee of the sliding leg is bent as the ball swings past the ankle and at the end position the shoulders are forward directly above the front knee (United States Bowling Congress, 2006).

To locate the starting position for the four-step approach the bowler starts at the foul line, similar to the one-step approach (Mullen, 2004). From here take four brisk strides away from the foul line and then after the fourth step add approximately another half step, this accommodates for the slide (Mullen, 2004; United States Bowling Congress, 2006; 2008). At this point turn and face in the direction of the pins and stand with feet together with the starting foot slightly forward (Mullen, 2004; United States Bowling Congress, 2006; 2008). The four-step approach allows the bowler to develop a consistent motion to the foul line that allows enough time for the swing to flow naturally (Mullen, 2004). For a right handed bowler, begin with the right foot and walk to the foul line in four steps: right, left, right, left (Mullen, 2004). Left handed bowlers start with the left foot and walk to the foul line in four steps: left, right, left, right (Mullen, 2004). The 
pace of the strides should be natural and comfortable to the bowler and should be performed in one fluid motion (United States Bowling Congress, 2008).

A five-step approach is a popular alternative to the four-step approach. In this approach the right handed bowler steps with the steps with the left foot before starting the four-step approach and vice versa for left handed bowlers (Mullen, 2004). This extra step allows for added momentum for the approach (Mullen, 2004).

With all three approaches it is important to the bowling game that the approach is performed in a linear motion (Mullen, 2004). Walking straight allows the bowler to create a relationship between the stance position and the target (Mullen, 2004). To establish this and to prevent drifting (poor alignment), the bowler must identify which board the foot starts on and the board of the final step (Mullen, 2004). This varies by the position of the pins and the angle at which to throw the ball.

\subsubsection{Wrist Position}

There are three different wrist positions the bowler may utilize: firm, relaxed, and strong. Each wrist position represents adjustments that allow for fine-tuning of the game (United States Bowling Congress, 2009). In relation to the ball, the firm wrist position will place the fingers down around the equator of the bowling ball at the time of release (United States Bowling Congress, 2009). This allows the fingers to remain in the ball long enough to allow the bowler to generate potential energy, revolutions to the ball and the potential to hook the ball (United States Bowling Congress, 2009). A relaxed wrist places the hand on top of the ball, above the equator, resulting in the fingers leaving the ball earlier (United States Bowling Congress, 2009). This creates a weak rolling ball with limited number of revolutions and travels a straighter path, reducing the potential of a hook (United States Bowling Congress, 2009). When a bowler 
maintains a strong wrist, the fingers remain in the ball longer and the athlete is in a position to create greater energy potential on the ball and increasing the number of revolutions to the bowling ball (United States Bowling Congress, 2009). It requires the athlete to be strong enough to place and maintain the hand well below the equator of the bowling ball (United States Bowling Congress, 2009).

\subsubsection{Armswing}

The initial movement of the ball and armswing is called the ball start. Once in the stance position and ball is in the appropriate starting point, the next step is to begin the pushaway movement of the ball (Mullen, 2004). The pushaway begins with the right leg for right handed bowlers or the left leg for left handed bowlers (Mullen, 2004). The elbow moves forward away from the sides to place the ball out in front in a position that initiates the movement of the upper arm and the swing starts from the shoulder, moving the entire arm (Mullen, 2004; United States Bowling Congress, 2009). Simultaneously, the non-bowling arm is supporting the weight of the ball throughout the entire pushaway phase of the arm swing (this is the end stage of the pushaway) (Mullen, 2004).

The next phase is the back swing. At the end of the pushaway, with relaxed muscles, allow arm to draw the ball back behind the body; the height is determined by the ball weight (Mullen, 2004). A relaxed arm and tension-free swing achieves high levels of consistency and accuracy which a critical component of being a good bowler (Mullen, 2004). Timing is another important aspect of bowling. It is the term used to describe the relationship between where the ball is located in relation to the bowler"s steps (United States Bowling Congress, 2009). Precise timing of the armswing with the footwork and approach are critical to the delivery of the ball onto the lane. 


\subsubsection{Delivery}

In the steps leading to the delivery, the momentum of the ball coming forward after the back swing creates a pendulum effect that allows the ball and arm to naturally move in a straight swing plane if the muscles are relaxed (Mullen, 2004). During the delivery phase, the spine is tilted forward 15 degrees and the upper body is directly over the individuals center of gravity which creates a strong leverage position (shoulders over the knees) (Mullen, 2004). The upper body position is similar to the stance position, but the support for the delivery is in the legs and not in the back (Mullen, 2004). On the last step towards the foul line, the bowler"s non-ball side foot should step forward into the slide as the ball arcs down returning forward from the backswing (Mullen, 2004; United States Bowling Congress, 2008; 2009). Simultaneously, the bowler should "sit down" lowering the lower body and while tilting the spine forward fifteen degrees with flexed knees to allow for a smooth delivery and a strong leverage position (Mullen, 2004; United States Bowling Congress, 2009).

The final step of bowling is the follow-through phase, or completing the momentum. With the hips low and the spine upright, the arm should follow through with the elbow ending up at least head high (Mullen, 2004). For a right handed bowlers, the right arm ends up at approximately the one o"clock position, with the left leg at six o"clock, the right leg at seven o"clock and the head at twelve o"clock (United States Bowling Congress, 2009). For left handed bowlers, the left arm ends up at approximately the eleven o"clock position, with the right leg at six o"clock, the left leg at five o"clock and the had at twelve o"clock (United States Bowling Congress, 2009). In bowling a strong finish entails a achieving a balance (timing and the arm swing) and maintaining optimal leverage (Mullen, 2004). This technique allows greater accuracy and constant ball velocity 
The sport of bowling involves repetitive use of the bowling arm with the addition of a weighted ball. The bowler must generate enough momentum by the proper body mechanics to move the ball down a forty-one and one half inch wide, sixty-foot lane that is designed to prevent the ball from traveling in a straight line making it a challenge to consistently knock down all ten pins. The correlation between other sports and its effects on BMD has been extensively studied over the years. However, the effect of the repetitive movements and the weight of the bowling ball in ten-pin bowling on the BMD in the forearm of the bowling arm at all levels of the sport, especially at the collegiate level is lacking in literature. 


\section{Chapter 3}

\section{METHODS}

\subsection{Participants}

The Wichita State University (WSU) Shocker Bowling program attracts more than fifty students from all over the United States and from other countries. The legacy of Shocker Bowling is enriched with coaching, team and individual victories along with numerous success stories. This includes the eighteen National Championships, nine men"s and nine women"s since the first national tournament in 1975 (Shocker Bowling, 2009). Within the USA, no other program exceeds WSU'es record (Shocker Bowling, 2009). Since the start of Shocker Bowling program, one hundred and sixty-nine members have achieved All-American status and seven members have been named National Bowlers-of-the-Year (Shocker Bowling, 2009). Over the past thirty-five years, thirty-two former and current members of WSU bowling have also been on Team USA (Shocker Bowling, 2009). The WSU women"s team is the only women"s team to be ranked in the top ten in the nation in every national poll for the past thirty-one years (Shocker Bowling, 2009). They have dominated the United States Bowling Congress (USBC) Intercollegiate Team Championship (ITC) since 1975 with thirty-four championships (Shocker Bowling, 2009). The men"s team has also been a powerful force in collegiate bowling. They have been ranked number one in the nation forty times, which is more than any other team (Shocker Bowling, 2009). The next highest is ranked number one a total of thirteen times.

The WSU Shocker Bowling team is considered to be an elite collegiate bowling team with participants of various ethnicities, from various countries and involved in ten-pin bowling at both the collegiate level and the international level. The participants for this study consisted of thirteen young adult males and twelve young adult females, all of whom are on the 2009-2010 
WSU Shocker Bowling team. This team consists of players from seven different countries (including the USA) and within the USA represents eleven different states. The average number of years this team has been bowling is $12.21 \pm 3.51$ years. As a team, the total number of years of experience in bowling is 293 years (males: 155 years, females: 138 years). A majority of the bowlers have been involved in competitive bowling since their adolescent years.

The WSU Shocker Bowling team identified which arm they use to bowl with and their dominant hand/arm was determined by which hand they used instinctively and efficiently to write. If the participants used their non-dominant hand/arm for bowling, that was noted. Of these twenty-five bowlers, twenty-three of them were right-hand/arm dominant and the remaining two were left-hand/arm dominant. Twenty-two of the bowlers used their dominant arm to bowl and the remaining three bowlers used their non-dominant arm.

The control group was recruited from the WSU campus, comprised of age-matched seven apparently healthy males and seven apparently healthy females, all nonbowlers, and not involved in any physical activity that affects the dominant or non-dominant upper extremity. The control group a mean $\pm(\mathrm{SD})$ for: age, body mass, and height of $21.36 \pm 2.27 \mathrm{yrs}, 70.84 \pm 17.63 \mathrm{~kg}$, and $172.46 \pm 8.49 \mathrm{~cm}$, respectively. Dominant hand/arm was again determined by which hand they used efficiently and instinctively to write. If the participants in the control group used their nondominant hand/arm for sports or other recreational activities, that was noted.

\subsection{Procedure}

Instructions for the pre-scan protocol were explained to the subjects prior to participation in the study. The subjects were instructed to limit intake of food and beverages at least four hours prior to scan. In addition, heavy workouts were also discouraged the day of the scan. Subjects dressed in light clothing that consisted of t-shirt and athletic shorts/pants, no shoes, and any 
exterior metal and jewelry were removed to avoid interference with the dual energy $\mathrm{x}$-ray absorptiometry (DXA) scan.

Upon arrival on test day the participants were informed of the studyes purpose, procedures, risks, and their right to remove themselves from the study at any time. They documented their informed written consent to participate in the study by signing a consent form approved by the Wichita Sate University Institutional Review Board (IRB) (see Appendix A \& B). Any consenting female participants were then asked to take a pregnancy test before any further participation in the study due to the risk of radiation exposure (Lloyd et al., 1998). Any positive pregnancy tests would result in exclusion from the study.

All testing for this study was performed in the Human Performance Laboratory located on the Wichita State University campus. Initial testing included obtaining anthropometric measurements and data required by the DXA software such as age, height, weight, gender, ethnicity, and forearm lengths. As required by Hologic software, height was measured to the nearest 0.1 inch (in) with use of standard wall-mounted stadiometer. Body mass was obtained to the nearest 0.1 kilogram $(\mathrm{kg})$ with a digital scale and forearm lengths were measured from the olecranon process to the most distal point of the ulnar styloid with standard small sliding calipers. A questionnaire was used to identify the subjects ${ }^{\text {ee }}$ demographics: age, gender, ethnicity, dominant hand, bowling arm.

Hologic QDR 4500W Elite Series DXA (Bedford, Massachusetts) and Software Version 12.3 was used to assess bone mineral density $(\mathrm{BMD})\left(\mathrm{g} / \mathrm{cm}^{2}\right)$, bone mineral content $(\mathrm{BMC})(\mathrm{g})$, lean tissue mass (LM) (g) and fat mass (FM) (g) and percentage of body fat. The dual-energy spectrum of the DXA is produced by using a low-energy spectrum waves of an X-ray beam (Griffith \& Genant, 2008). The minimal radiation exposure from the beams projects an image 
that measures areal density and body composition in a timely manner (Fuerst et al., 1995; Griffith \& Genant, 2008; Lohman et al., 2009). Using the BMD and subject demographics, the DXA software calculates Z-scores and T-scores. A Z-score compares the bone density measurement to an age-matched reference position by scaling the raw measurement $(\mathrm{g} / \mathrm{cm} 2)$ to describe the number of SD (Carey et al., 2007). Z-scores can also be adjusted for gender, ethnicity, and weight. T-scores compares BMD measurement in a similar manner but using a young adult reference population that has presumably reached peak bone mass (Carey et al., 2007). The measurements of bone density with DXA technology has been validated and widely accepted (Carey et al., 2007). To ensure the stability of the DXA equipment, quality-control scans were performed daily with an anthropometric spine phantom and monthly phantom measurements as provided and controlled by the manufacturer.

Following the pre-scan protocol, the DXA was used to scan the areas of interest for this study, which included three regional scans, (1) dominant distal forearm, (2) non-dominant distal forearm and (3) total-body. Manufacturer protocol was followed precisely for the DXA scans as follows. The DXA scan of left and right forearms, the distal 1/3, was assessed while the participant sits adjacent to the DXA bed with their forearm resting in a motionless pronated position on a forearm positioning adaptive device provided by Hologic. The scan required 10 to 20 seconds while the DXA arm scans over the forearm. For the total-body scan, the participants were in a supine position lying motionless on the scanning table during the approximately six minute scan. The tissue composition of the arms was determined from the regional analysis of the total-body DXA scan. The arm region included the hand, forearm, and arm and was separated from the trunk by an inclined line crossing the scapula-humeral joint. 
The scans were performed and analyzed with the manufacturer ${ }^{\text {ee }}$ s software by an experienced technician. The data were stored on a password-protected computer and any hard copies were stored in a locked file cabinet with the identity of the subjects kept confidential by use of an assigned identification number.

\subsection{Statistical Analysis}

The side-to-side differences in forearm and arm BMD were expressed as the percentage of the dominant value (relative difference): percentage of difference $(\%)=[($ dominant nondominant)/nondominant] x 100. The significance of side-to-side difference between groups was determined using the One-Sample T-test and one-way ANOVA. All tests of statistical significance were set at $\mathrm{p}<0.05$. Descriptive statistics were used to analyze body mass, height, body mass index, age, body composition and bowling career history for both groups. All data were statistically analyzed with the Statistical Package for the Social Sciences software system PASW, version 18.0 (SPSS Inc, Chicago, IL). 


\section{Chapter 4}

\section{RESULTS}

\subsection{Participants}

Participant characteristics and bowling career history are in Table 4.1. The participants consisted of twenty-five collegiate ten-pin bowlers recruited from the 2009-2010 Wichita State University Shocker Bowling Team and fourteen non-bowlers designated as the control group. All thirty-nine participants in this study were between the ages of eighteen and twenty-four. The collegiate bowlers execute approximately 400-500 arm movements per day with their bowling balls, including practice sessions and tournament tours. No difference existed in the anthropometric data between the bowling team and control group.

TABLE 4.1

ANTHROPOMETRIC DATA FOR BOWLING TEAM AND CONTROL GROUP

\begin{tabular}{lcc}
\hline & \multicolumn{2}{c}{ PARTICIPANTS } \\
\cline { 2 - 3 } Variables & Bowlers (N=25) & Controls (N=14) \\
\hline Age (yrs) & $20.72 \pm 1.46$ & $21.36 \pm 2.27$ \\
Height (cm) & $170.11 \pm 11.05$ & $172.46 \pm 8.49$ \\
Weight (kg) & $75.17 \pm 15.68$ & $70.84 \pm 17.63$ \\
& & $23.49 \pm 3.88$ \\
BMI (weight/[height $\left.]^{2}\right)$ & $25.74 \pm 3.39$ & $23.86 \pm 6.93$ \\
Body Fat (\%) & & \\
Bowling Career (yrs) & $27.14 \pm 5.48$ & - \\
\hline
\end{tabular}

Values are expressed as mean $\pm \mathrm{SD}$ 


\subsection{Bone Mineral Density}

Bone mineral density (BMD) values for the bowling teams ${ }^{\text {ec }}$ bowling forearm ranged from $0.542 \mathrm{~g} / \mathrm{cm}^{2}$ to $0.750 \mathrm{~g} / \mathrm{cm}^{2}$. Summary data for all BMD measurements are in Table 4.2 and Table 4.3. A comparison of BMD between the groups is in Table 4.4. All values were significant if $p<0.05$. A one-way ANOVA test revealed no statistical significance in bowling forearm and non-bowling forearm between the groups (bowling forearm BMD: $\mathrm{p}=0.549$; non-bowling forearm BMD: $p=0.413)$. The General Linear Model Multivariate test showed that there is a significant difference between groups when separated by gender for both the bowling and nonbowling forearm BMD $(p<0.001))$. Bowling forearm BMD is significantly greater between groups and gender compared to the non-bowling forearm $(\mathrm{p}<0.05)$. The comparison of BMD between genders is in Tables 4.5 and 4.6.

One-Sample T-test revealed the following. Both male and female bowlers showed significant difference between their bowling arm and non-bowling arm. Similar results observed in the males and females of the control group. In comparison of the BMD of the bowling arm and non-bowling arm, results show no statistical difference between groups, but significant difference between genders. The results from the total body BMD follows the same pattern as the forearm and arm BMD, no significance between groups, but significant between genders.

Table 4.7 shows the difference between the forearm and arms. The female bowlers have the greatest percentage of difference in side-to-side comparison of forearm BMD with the bowling forearm being significantly greater then the non-bowling arm $(4.06 \pm 3.11 \%, \mathrm{p}<0.05)$. All groups showed significantly greater BMD in the bowling arm compared to the non-bowling arm (male bowlers: $1.48 \pm 2.62 \%, \mathrm{p}<0.05$; male controls: $1.56 \pm 2.31 \%, \mathrm{p}<0.05$; female controls: $1.88 \pm 2.13 \%, \mathrm{p}<0.05)$, which is illustrated in Figure 4.1. The percentage of difference for the 
side-to-side difference was calculated by the following equation: percentage of difference $(\%)=$ [(bowling forearm - non-bowling forearm)/non-bowling forearm] x 100 .

TABLE 4.2

BOWLING TEAM BMD MEASUREMENTS

\begin{tabular}{lccccc}
\hline & \multicolumn{5}{c}{ BONE MINERAL DENSITY $\left(\mathrm{g} / \mathrm{cm}^{2}\right)$} \\
\cline { 2 - 6 } & $\mathrm{N}$ & Min & Max & Mean & SD \\
\hline Bowling Forearm & 25 & 0.542 & 0.750 & 0.635 & 0.049 \\
Non-Bowling Forearm & 25 & 0.524 & 0.727 & 0.618 & 0.055 \\
Bowling Arm & 25 & 0.725 & 0.980 & 0.849 & 0.070 \\
Non-Bowling Arm & 25 & 0.695 & 0.941 & 0.815 & 0.066 \\
Total Body & 25 & 1.087 & 1.357 & 1.240 & 0.072 \\
\hline
\end{tabular}

TABLE 4.3

CONTROL GROUP BMD MEASUREMENTS

\begin{tabular}{lccccc}
\hline & \multicolumn{5}{c}{ BONE MINERAL DENSITY $\left(\mathrm{g} / \mathrm{cm}^{2}\right)$} \\
\cline { 2 - 6 } & $\mathrm{N}$ & Min & Max & Mean & SD \\
\hline Bowling Forearm & 14 & 0.544 & 0.921 & 0.65007 & 0.10283 \\
Non-Bowling Forearm & 14 & 0.526 & 0.878 & 0.63871 & 0.0993 \\
Bowling Arm & 14 & 0.74 & 1.132 & 0.86 & 0.12835 \\
Non-Bowling Arm & 14 & 0.698 & 1.084 & 0.82229 & 0.11643 \\
Total Body & 14 & 1.057 & 1.478 & 1.21464 & 0.12881 \\
\hline
\end{tabular}


TABLE 4.4

COMPARISON OF BMD VALUES BETWEEN GROUPS

\begin{tabular}{lcc}
\hline & \multicolumn{2}{c}{ BONE MINERAL DENSITY $\left(\mathrm{g} / \mathrm{cm}^{2}\right)$} \\
\cline { 2 - 3 } & $\begin{array}{c}\text { Bowlers } \\
(\mathrm{N}=25)\end{array}$ & $\begin{array}{c}\text { Controls } \\
(\mathrm{N}=14)\end{array}$ \\
\hline Bowling Forearm & $0.635 \pm 0.049$ & $0.650 \pm 0.102$ \\
Non-Bowling Forearm & $0.618 \pm 0.055$ & $0.639 \pm 0.099$ \\
Bowling Arm & $0.849 \pm 0.070$ & $0.860 \pm 0.128$ \\
Non-Bowling Arm & $0.815 \pm 0.066$ & $0.822 \pm 0.116$ \\
Total Body & $1.240 \pm 0.072$ & $1.215 \pm 0.129$ \\
\hline
\end{tabular}

Values are expressed as mean \pm SD

* Significantly different between groups $(p<0.05)$

TABLE 4.5

BMD VALUES FOR BOWLING TEAM

\begin{tabular}{lcc}
\hline & \multicolumn{2}{c}{ BONE MINERAL DENSITY $\left(\mathrm{g} / \mathrm{cm}^{2}\right)$} \\
\cline { 2 - 3 } & \multicolumn{2}{c}{ MOWLERS } \\
\cline { 2 - 3 } & $(\mathrm{N}=13)$ & $\begin{array}{c}\text { Females } \\
(\mathrm{N}=12)\end{array}$ \\
\hline Bowling Forearm & $0.663 \pm 0.041^{*}$ & $0.605 \pm 0.040^{*}$ \\
Non-Bowling Forearm & $0.654 \pm 0.046^{*}$ & $0.580 \pm 0.035^{*}$ \\
Bowling Arm & $0.899 \pm 0.050^{*}$ & $0.796 \pm 0.046^{*}$ \\
Non-Bowling Arm & $0.863 \pm 0.042^{*}$ & $0.763 \pm 0.045^{*}$ \\
Total Body & $1.259 \pm 0.064^{*}$ & $1.221 \pm 0.078^{*}$ \\
\hline
\end{tabular}

Values are expressed as mean \pm SD

* Significantly different between groups $(\mathrm{p}<0.05)$ 
TABLE 4.6

BMD VALUES FOR CONTROL GROUP

\begin{tabular}{lcc}
\hline & \multicolumn{2}{c}{ BONE MINERAL DENSITY $\left(\mathrm{g} / \mathrm{cm}^{2}\right)$} \\
\cline { 2 - 3 } & $\begin{array}{c}\text { Males } \\
(\mathrm{N}=7)\end{array}$ & $\begin{array}{c}\text { Females } \\
(\mathrm{N}=7)\end{array}$ \\
\cline { 2 - 3 } Bowling Forearm & $0.721 \pm 0.100^{*}$ & $0.579 \pm 0.035^{*}$ \\
Non-Bowling Forearm & $0.709 \pm 0.089^{*}$ & $0.569 \pm 0.044^{*}$ \\
Bowling Arm & $0.955 \pm 0.114^{*}$ & $0.765 \pm 0.040^{*}$ \\
Non-Bowling Arm & $0.907 \pm 0.104^{*}$ & $0.738 \pm 0.045^{*}$ \\
Total Body & $1.296 \pm 0.112^{*}$ & $1.133 \pm 0.089^{*}$ \\
\hline Vacs a
\end{tabular}

Values are expressed as mean \pm SD

* Significantly different between genders $(\mathrm{p}<0.05)$

TABLE 4.7

DIFFERENCE BETWEEN BOWLING AND NON-BOWLING ARM

\begin{tabular}{lcccc}
\hline & \multicolumn{4}{c}{ Bone Mineral Density $\left(\mathrm{g} / \mathrm{cm}^{2}\right)$} \\
\cline { 2 - 5 } & \multicolumn{2}{c}{ BOWLERS } & \multicolumn{2}{c}{ CONTROLS } \\
\cline { 2 - 5 } & $\begin{array}{c}\text { Males } \\
\text { N=13) }\end{array}$ & $\begin{array}{c}\text { Females } \\
(\mathrm{N}=12)\end{array}$ & $\begin{array}{c}\text { Males } \\
(\mathrm{N}=7)\end{array}$ & $\begin{array}{c}\text { Females } \\
(\mathrm{N}=7)\end{array}$ \\
\hline Forearm & $0.010 \pm 0.017^{*}$ & $0.025 \pm 0.020^{*}$ & $0.012 \pm 0.019^{*}$ & $0.010 \pm 0.012^{*}$ \\
Arm & $0.036 \pm 0.050^{*}$ & $0.033 \pm 0.021^{*}$ & $0.048 \pm 0.034^{*}$ & $0.027 \pm 0.015^{*}$ \\
\hline Vayyyyyy
\end{tabular}

Values are expressed as mean \pm SD

* Significantly different between genders $(\mathrm{p}<0.05)$ 


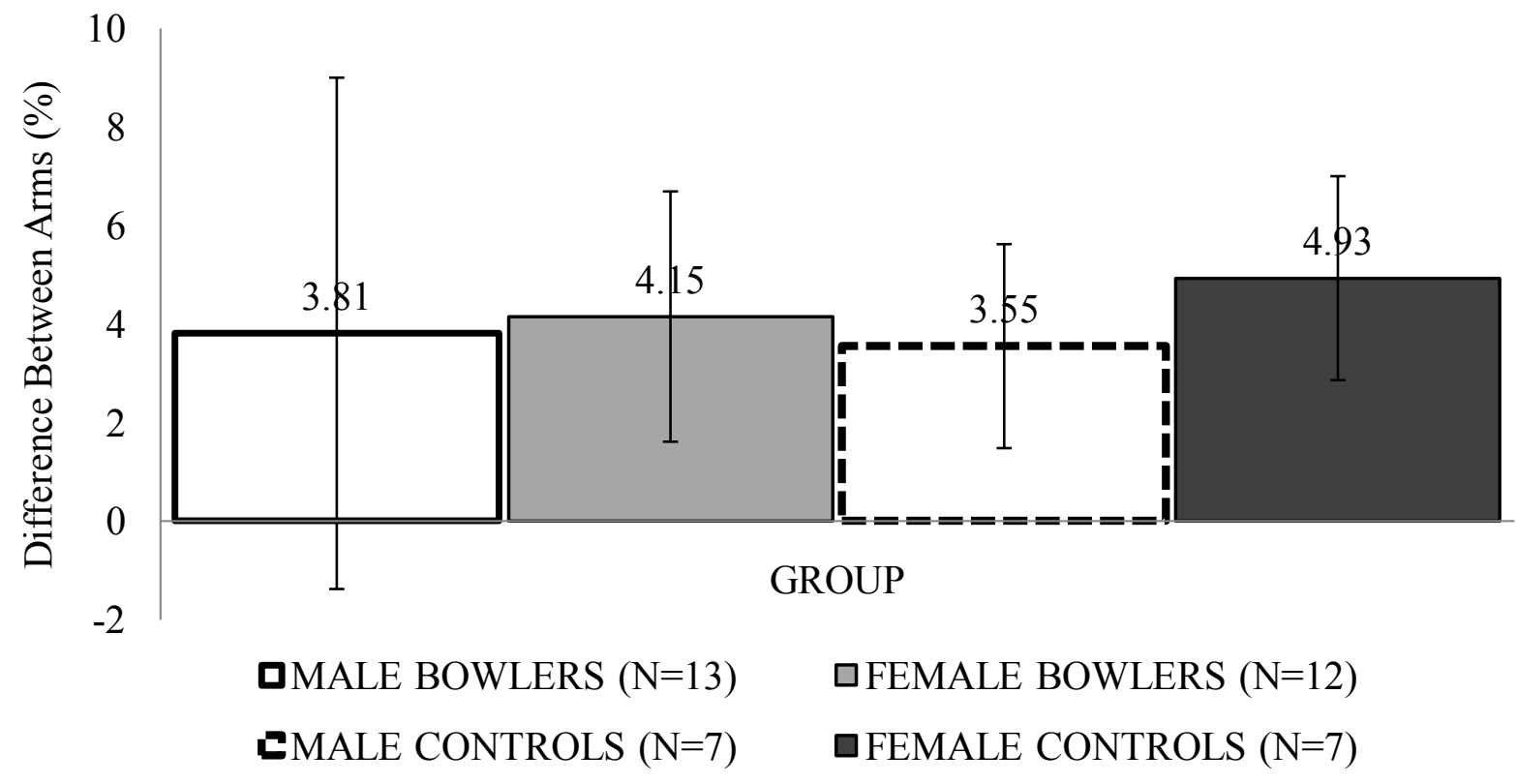

FIGURE 4.1 Relative differences between bowling and non-bowling arm BMD; Percentage of difference $=[$ (bowling arm - non-bowling arm $) /$ non-bowling arm $] \times 100$. The bars represent the SD (\%).

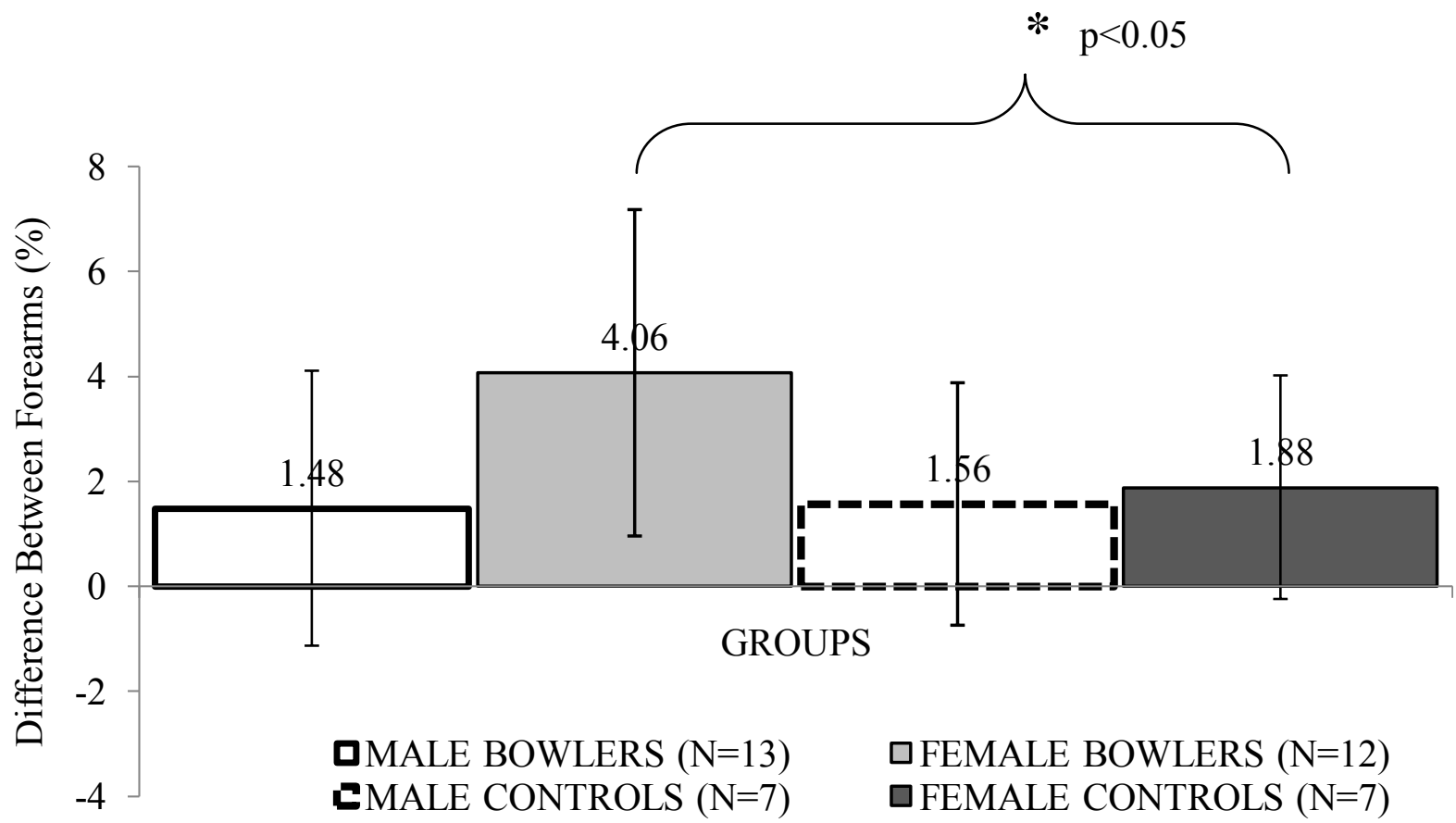

FIGURE 4.2 Relative differences between bowling and non-bowling forearm BMD; Percentage of difference $=[($ bowling forearm - non-bowling forearm $) /$ non-bowling forearm $] \mathrm{x} 100$. The bars represent the $\mathrm{SD}(\%)$. 


\section{Chapter 5}

\section{DISCUSSION}

The present study revealed that both male and female ten-pin bowlers, exhibit significantly higher bone mineral density (BMD) of their bowling arm compared to their nonbowling arm and compared to the dominant arm of the control group. This study determined the

forearm BMD of an elite collegiate ten-pin bowling team and to the best the author"s knowledge; this is the first study to examine the effects of ten-pin bowling on the forearm BMD of bowlers competing at the elite collegiate level with the use of a dual energy $\mathrm{x}$-ray absorptiometry unit (DXA). Numerous studies have documented that the effects of exercise on bone density is osteogenic and is a key component in maintaining bone health. The findings in this study are similar to other studies that have examined elite or collegiate players involved high repetitive preferentially loading on the dominant arm, such as volleyball, racquet and throwing athletes.

The most efficacious period of bone density growth is during the first two decades of life. It is in this phase of life that peak bone mass is typically obtained. The ten-pin bowlers participating in this study were between the ages of eighteen to twenty-four years old. The age of these participants are important to note because they represent the end of the period of when peak bone mass is achieved. Many athletes begin their sports career at a young age. These are the athletes that have shown greater osteogenic effect on bone and attainment of higher peak bone mass (Nichols et al., 2007). The increase in bone mass could be predicted to be positively associated in the reduction of risk for fractures later in life (Nichols et al., 2007). The participants in this study have been bowling throughout their adolescent years, six to eighteen years. In addition, these participants were representative of seven different countries and eleven different states in the USA. This knowledge is important because these participants represent diversity in 
many areas, such as cultures nutritional influences and various environmental factors, all of which play a role in bone health.

The focus of this cross-sectional study was to determine whether the high volume and high impact of repetitive arm movement with the addition of the weighted bowling ball produced in collegiate ten-pin bowling would be reflected in the forearm BMD of the bowling arm. The repetitive loading mechanics of the bowling arm are similar to the other sports that involve dominant use of one limb. Such sports include volleyball, baseball, and tennis. Other studies have also looked at the effect of sports that do not typically involve the use of the upper extremities such as endurance running, swimming, and cycling on BMD of the arms. The topics of this discussion are three-fold: (1) to review the effects of sports on BMD that preferentially load on the dominant arm (table 5.1), (2) to analyze the effects of ten-pin bowling on forearm and arm BMD, and (3) to compare the results of the present study with studies of other sports (Figures 5.1, 5.2, and 5.3).

\subsection{Collegiate Sports and Forearm/Arm BMD}

The effect of mechanotransduction on bone tissue has consistently been shown between athletes participating in sports involving high ground reaction forces (GRF) and those participating in low- or no-impact sports and are associated with bone health (Bailey \& BrookeWavell, 2008; Kohrt et al., 2004; Morel et al., 2001; Nichols et al., 2007; Nikander et al., 2005). In addition total-body BMD is greater in weight bearing sports than in non-weight bearing sports (Morel et al., 2001). In throwing sports, the athletes"e arm predominantly used to throw an object (dependent upon the sport) positively responds to the mechanical loading placed on that dominant throwing arm. This has been shown by analyzing the effect of various throwing sports on bone density (McClanahan et al., 2002; Mudd et al., 2007; Neil \& Schweitzer, 2008; Shaw \& 
Stock, 2009; Warden et al., 2009; Whittington et al., 2009). Throwing sports include baseball, softball, cricket, javelin, shot put, discus, etc. Only six studies have been done on collegiate level throwing sports and bone density in response to unilateral loading on the upper extremity. Throwing sports are similar to the sport of bowling in the manner of the mechanics of bowling compared to throwing and the addition of throwing a weighted object placing force on the bowling arm. A limited number of studies have analyzed these sports and their effect on BMD at a collegiate level, especially at the site of the forearm.

Warden, et al. studied fifteen male baseball throwers, and found that throwing induces substantial torsional adaptation within the midshaft humerus of the subjects (Warden et al., 2009). The throwers had substantially greater side-to-side differences in skeletal tissue of the upper extremities compared to the controls which can be correlated to the habitual loading of the dominant upper extremity and influenced by the playing position of the athlete (Warden et al., 2009). The upper extremity areal BMD (aBMD) of throwers was $0.92 \pm 0.09 \mathrm{~g} / \mathrm{cm}^{2}, \mathrm{p}<0.05$ compared to the controls $\left(0.86 \pm 0.04 \mathrm{~g} / \mathrm{cm}^{2}, \mathrm{p}<0.05\right)$ (Warden et al., 2009). No effect of throwing was observed in midshaft or distal radius bone density (Warden et al., 2009). Neil \& Schweitzer also studied the effects of baseball, but focused on the humeral cortical and trabecular bone tissue response to throwing (Neil \& Schweitzer, 2008). They observed significant side-to-side differences with the throwing arm greater than the non-throwing arm at all sites of the humeri (Neil \& Schweitzer, 2008).

Shaw \& Stock studied the effect of cricket on bone strength compared to swimmers (Shaw \& Stock, 2009). In this study the observed that there was an increase in ulna rigidity in the cricket players compared to swimmers and controls (Shaw \& Stock, 2009). In addition the bilateral asymmetry in humeral rigidity was greater among cricketers than swimmers and 
TABLE 5.1

EFFECT OF ARM DOMINANCE IN VOLLEYBALL, RACQUET AND THROWING ATHLETES AGED 18-24 YEARS ON FOREARM AND ARM BONE DENSITY

\begin{tabular}{|c|c|c|c|c|c|c|c|}
\hline Author & Sport & Exp. & $\begin{array}{l}\text { Mean Age } \\
(\mathrm{yr})\end{array}$ & Cont. & Scan Type & Scans & Results \\
\hline $\begin{array}{l}\text { Warden, et al., } \\
\qquad 2009\end{array}$ & $\mathrm{BA}$ & $15 \mathrm{M}$ & 19.9 & $15 \mathrm{M}$ & DXA, pQCT & $\begin{array}{l}\text { TB, HU, } \\
\text { MR, DR }\end{array}$ & $\begin{array}{c}\uparrow \mathrm{TB}, \mathrm{S}, \mathrm{HP} \text { aBMD, side-to-side diff in } \mathrm{A} \\
\mathrm{BMC} \text {, no diff in MR or DR }\end{array}$ \\
\hline $\begin{array}{l}\text { Shaw and } \\
\text { Stock, } 2009\end{array}$ & CR, SW & $51 \mathrm{M}$ & 22 & $20 \mathrm{M}$ & pQCT & HU, Ulna & Ulna rigidity $\uparrow$ in $\mathrm{CR}$ than SW \& controls \\
\hline $\begin{array}{l}\text { Whittington, } \\
\text { et al., } 2009\end{array}$ & $\mathrm{TH}$ & $\begin{array}{c}4 \mathrm{M}, 3 \\
\mathrm{~F}\end{array}$ & 19 & $\begin{array}{l}6 \mathrm{M} \\
8 \mathrm{~F}\end{array}$ & DXA & $\mathrm{A}$ & Dom A BMD slightly $\uparrow$ than non-dom A \\
\hline $\begin{array}{l}\text { Neil and } \\
\text { Schweitzer, } \\
2008\end{array}$ & BA & $8 \mathrm{M}$ & 19.8 & - & pQCT & A & $\begin{array}{c}\text { Side-to-side diff of cortical \& trabecular } \\
\text { bone favors throwing arm }\end{array}$ \\
\hline $\begin{array}{l}\text { Ducher, et al., } \\
2005\end{array}$ & $\mathrm{TN}$ & $\begin{array}{l}10 \mathrm{M} \\
10 \mathrm{~F}\end{array}$ & 23 & - & $\begin{array}{l}\text { DXA Delphi, } \\
\text { MRI }\end{array}$ & FA, DR & $\begin{array}{l}\uparrow \text { side-to-side diff in cortical volume in } \\
\text { one-handed backhand players }\end{array}$ \\
\hline $\begin{array}{l}\text { Ashizawa, et } \\
\text { al., } 1999\end{array}$ & $\mathrm{TN}$ & $\begin{array}{c}6 \mathrm{M}, 10 \\
\mathrm{~F}\end{array}$ & 20.3 & $\begin{array}{l}5 \mathrm{M} \\
7 \mathrm{~F}\end{array}$ & $\begin{array}{l}\text { pQCT XCT } \\
960\end{array}$ & MR \& DR & $\begin{array}{l}\text { MR: } \uparrow \text { BMC all areas in playing arm vs } \\
\text { nonplaying arm; DR: similar results } \\
\text { except in the trabecular bone }\end{array}$ \\
\hline $\begin{array}{l}\text { Ducher, et al., } \\
2004\end{array}$ & $\mathrm{TN}$ & $\begin{array}{l}33 \mathrm{M} \\
24 \mathrm{~F}\end{array}$ & 24 & - & $\begin{array}{l}\text { DXA Delpi } \\
\text { QDR }\end{array}$ & FA, TB & $\begin{array}{c}\text { 19.8\% BMC side-to-side diff \& } 10.9 \% \\
\text { BMD; M: greater asymmetry vs F for } \\
\text { BMC \& BMD }\end{array}$ \\
\hline $\begin{array}{l}\text { McClanahan, } \\
\text { et al., } 2002\end{array}$ & $\begin{array}{l}\text { BA, BB, } \\
\text { FB, G, SC, } \\
\text { TN, CC, } \\
\text { TR, VB }\end{array}$ & $\begin{array}{l}121 \mathrm{M} \\
63 \mathrm{~F}\end{array}$ & - & - & $\begin{array}{l}\text { DXA QDR } \\
2000\end{array}$ & A & $\begin{array}{c}\text { Rt A BMD sig } \uparrow \text { than lt A for all M \& } \\
\text { and F teams }\end{array}$ \\
\hline
\end{tabular}


TABLE 5.1 (continued)

EFFECT OF ARM DOMINANCE IN VOLLEYBALL, RACQUET AND THROWING ATHLETES AGED 18-24 YEARS ON FOREARM AND ARM BONE DENSITY

\begin{tabular}{|c|c|c|c|c|c|c|c|}
\hline Author & Sport & Exp. & $\begin{array}{l}\text { Mean Age } \\
(\mathrm{yr})\end{array}$ & Cont. & Scan Type & Scans & Results \\
\hline $\begin{array}{l}\text { Nikander, et } \\
\text { al., } 2006\end{array}$ & $\begin{array}{l}\text { VB, RS, } \\
\mathrm{HR}, \mathrm{SC} \\
\quad \mathrm{SW}\end{array}$ & $113 \mathrm{~F}$ & 21.9 & $30 \mathrm{~F}$ & $\begin{array}{c}\mathrm{pQCT} \\
\mathrm{XCT} 3000\end{array}$ & $\begin{array}{l}\text { DR, R HU, } \\
\text { tibia }\end{array}$ & $\begin{array}{l}\text { BMC at DR \& HU sig } \uparrow \text { vs cont; RS: } \\
\text { cortical of DR \& HU thicker than cont }\end{array}$ \\
\hline $\begin{array}{l}\text { Alfredson, et } \\
\text { al., } 1997\end{array}$ & VB & $13 \mathrm{~F}$ & 23 & 13 & $\begin{array}{l}\text { DXA } \\
\text { Lunar } \\
\text { DPX-L }\end{array}$ & $\begin{array}{l}\text { TB, LS, } \\
\text { FN, HU }\end{array}$ & $\begin{array}{c}\text { Dom HU in VB sig } \uparrow \text { BMD values than } \\
\text { the non-dom HU \& the dom HU of the } \\
\text { cont }\end{array}$ \\
\hline $\begin{array}{l}\text { Alfredson, et } \\
\text { al., } 1998\end{array}$ & VB & 11 & 23.3 & 11 & $\begin{array}{l}\text { DXA } \\
\text { Lunar } \\
\text { DPX-L }\end{array}$ & $\mathrm{TB}, \mathrm{DR}$ & $\begin{array}{c}\text { Distal HU BMC \& DR BMD no sig diff } \\
\text { between groups; HU \& DR sig } \uparrow \text { in dom } \\
\text { vs non-dom }\end{array}$ \\
\hline \multicolumn{8}{|c|}{$\begin{array}{l}\text { Abbreviations: TH (throwers); BA (baseball); TN (tennis); CR (cricket); VB (volleyball); RS (racquet sports); HR (hurdlers); SC } \\
\text { (soccer); SW (swimming); BB (basketball); FB (football); G (golf); CC (cross country); TR (track); M (male); F (female); dom } \\
\text { (dominant); non-dom (non-dominant); diff (difference); sig. (significantly); A (arm); FA (forearm); DR (distal radius); MR (mid } \\
\text { radius); R (radius); HU (humerus); TB (total body); LS (lumbar spine); FN (femoral neck); Exp (experimental group); cont (control } \\
\text { group) }\end{array}$} \\
\hline
\end{tabular}


controls (Shaw \& Stock, 2009). Whittington, et al. studied the BMD of shot put, discus, weight throwers, hammer throw and javelin (Whittington et al., 2009). In this study, the dominant arm BMD was slightly greater compared to the non-dominant arm for both males and females (Whittington et al., 2009). The results form these studies on throwing athletes show similar data as observed in this study. The preferential loading of one arm in bowling is similar to the concept of throwing sports that involve releasing a weighted object a specific distance.

In racquet sports, the same osteogenic effect on the dominant playing arm has been observed and is similar to that seen in throwing sports. The force generated by the ball onto the racquet is enough to produce an effect on the BMD of athletes involved in racquet sports such as tennis. Like the throwing studies, a small number of studies have looked at collegiate level athletes and BMD. Ducher, et al. they studied tennis players and observed volumetric BMD (vBMD) of the dominant forearm to be slightly higher than the non-dominant forearm (637.7 \pm 86.1 vs $616 \pm 75.2 \mathrm{mg} \cdot \mathrm{cm}^{-3}, \mathrm{p}<005$ ), with an asymmetry of 3.3\% (Ducher et al., 2005). Ashizawa, et al. showed greater BMD of the playing arm than the non-playing arm at periosteal bone area, total bone BMD, trabecular bone are and trabecular BMD (Ashizawa et al., 1999). In the non-dominant radius, no significant differences were found between their control group and the tennis players (Ashizawa et al., 1999). In different study done by Ducher, et al. they found a $10.9 \%$ side-to-side difference in one-handed backhand tennis players compared to $5.1 \%$ side-toside difference in two-handed backhand tennis players (Ducher et al., 2004). This asymmetry was observed to be greater in the men than in women at the ultradistal radius BMD (Ducher et al., 2004).

One other sport that can be related to the sport of bowling is volleyball. Volleyball involves impact loading on the dominant arm of the athlete. Alfredson, et al. found similar 
results as in the previously mentioned studies. They observed the affect of volleyball on BMD of the distal radius (Alfredson et al., 1998). The study showed that the volleyball players had significantly higher BMD in the distal radius compared with the nondominant arm, but no significant difference between the groups which is consistent with the results from this ten-pin bowling study (Alfredson et al., 1998).

\subsection{Ten-pin Bowling BMD compared to Controls}

The WSU Shocker Bowling team"s total body BMD was not significantly greater than the total body BMD of the control group ( $\mathrm{p}=0.425$ ). This is not surprising, because frequently, weightlifting is a supplementation component in various sports used to enhance performance. Studies have shown that weightlifting exercises can significantly increase bone mass of the upper limbs (Hamdy et al., 1994; Nevill et al., 2004; Nikander et al., 2005). In addition, non-athletes that are physically active typically include weightlifting exercises in their workout regimens to enhance self-image and health. Therefore, since both the bowling team and the control groups of this study include weight-bearing activities, the total body BMD difference between the two groups would not be expected to be different.

The side-to-side difference of the forearm BMD in the WSU Shocker Bowling team was $2.72 \pm 3.10 \%$ compared to the controls whose side-to-side difference of the forearm BMD was $1.72 \pm 2.14 \%$. Yet, contralateral forearm difference was not statistically significant. The side-toside difference of the arm BMD was slightly greater in the bowling arm of the controls $(4.24 \pm$ $2.91 \%)$ compared to the bowling team $(3.97 \pm 2.91)$. However, this difference is also not statistically significant. This could be a result of the bowling team performing bilateral upper extremity resistance training so as to not isolating only the bowling arm. Another explanation is that there are three bowlers in this study that bowling with the opposite hand/arm that they 
naturally and predominantly use to write. When excluding those three subjects and reanalyzing the data, significant difference were found between the bowling forearm and arm of the male and female bowlers, with similar results for the non-bowing forearm and arm. However, as in the previous results found in this study, there were no significant difference between the groups, until separated by gender.

When separated by gender the comparison of the bowling arm to the non-bowling arm revealed some significant differences. Comparison of the bowling forearm to the non-bowling forearm within the group of male bowlers, the BMD was significantly greater in the bowling forearm. Similar results were observed in the males of the control group. For the male bowlers the forearm BMD was less than the control group males, and the side-to-side relative difference was $1.48 \pm 2.14 \%, p<0.05$ for the male bowlers and $1.56 \pm 2.31 \%, p<0.05$ in the controls. The males in the control group had no difference between the bowling forearm and non-bowling forearm. As for the bowling arm BMD, the male bowlers difference between bowling arm and non-bowling arm compared to the male controls $(3.81 \pm 5.19 \%$ and $3.55 \pm 2.07, \mathrm{p}<0.05$ respectively).

Comparison of the bowling forearm to the non-bowling forearm within the group of female bowlers, the BMD was significantly greater in the bowling forearm. As with the males, similar results were observed in the females of the control group. For the female bowlers the forearm BMD was greater than the control group females, and the side-to-side relative difference was $4.06 \pm 3.11 \%, \mathrm{p}<0.05$ compared to the $1.88 \pm 2.13 \%, \mathrm{p}<0.05$ difference for the female controls. The bowling arm BMD for the females bowlers had a less contralateral difference compared to the female controls $(4.15 \pm 2.54 \%$ and $4.93 \% \pm 2.07 \%, \mathrm{p}<0.05$ respectively). 
Within the bowling team, the females exhibited the greatest relative difference in forearm BMD compared to the male bowlers and the controls. This can be explained by the difference in the approach of the wrist position and bowling ball release between the genders. The male bowlers in this study generally maintain a firm wrist during the bowling process and at the end during the release of the ball. For the female bowlers in this study, they use the relaxed wrist approach when holding the bowling ball and at the point of release. This involves a greater amount of forearm flexion which results in extra tension on the bone by the forearm flexors. Muscle action is known to be an important part in stimulating the bone remodeling process. This key information in regards to the participants " bowling mechanics plays an important role in the side-to-side difference of the bowling forearm and the non-bowling forearm. From this study, it can be determined that ten-pin bowling stimulates the bone remodeling process greater in the bowling arm compared to the non-bowling arm. In addition, the bowling mechanics of the athlete also plays a key factor in generating a greater response in the bowling arm compared to the nonbowling arm as a result of the impact force of the bowling ball.

\subsection{Ten-pin Bowling BMD Compared to Other Collegiate Sports}

Bowling like other sports requires time and dedication to the sport in order to be a good athlete. This involves both practice and tournament games. Most sports promote bone remodeling which results in an increased BMD. This study has shown that ten-pin bowling at an elite collegiate level produces an increased BMD of the bowling arm and forearm compared to the non-bowling arm and the control group when separated by gender and group. The results from this study are consistent with the findings of the studies mentioned in Table 5.1. However, how does the effect of ten-pin bowling on forearm and arm BMD compare to other sports? 


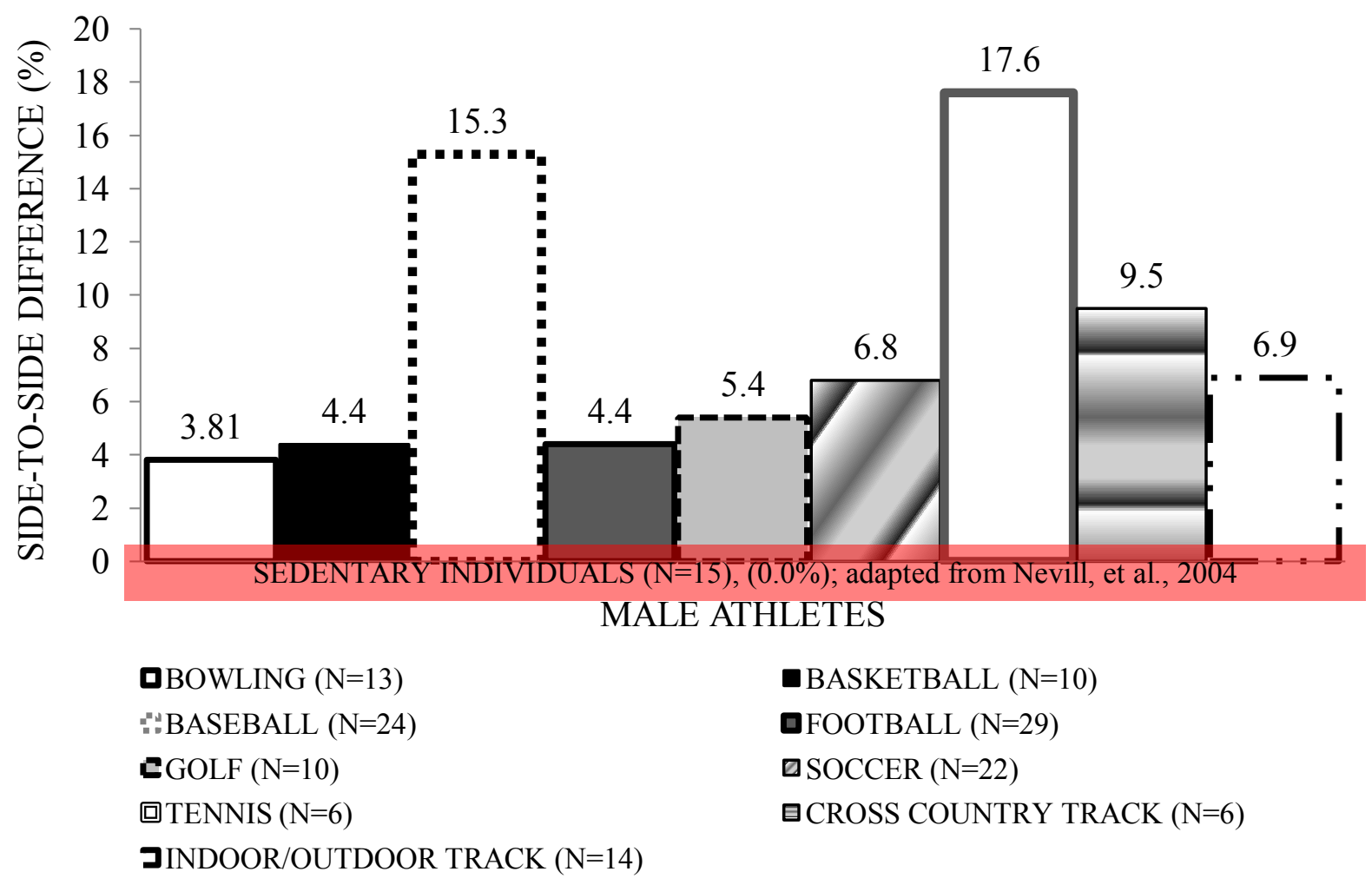

FIGURE 5.1 Comparison of side-to-side arm BMD relative difference between McClanahan, et al., 2002 and Male Bowlers

McClanahan, et al. did a study on BMD of contralateral arms of various male and female sports on NCAA Division I athletes (McClanahan et al., 2002).

The results of their study were used to make a comparison of side-to-side arm BMD relative differences of nine different sports to ten-pin bowling by gender (Figure $5.1 \& 5.2$ ). Tenpin bowling compared to the nine sports studied in McClanahan et al. appears to have the least effect on the side-to-side difference of arm BMD for both male and female bowlers. It is interesting that bowling did not produce more of a side-to-side difference than soccer and track, since both soccer and most track events involve very little arm movement compared to the extensive amount of unilateral arm movement involved in the sport of bowling, especially at an elite level. 


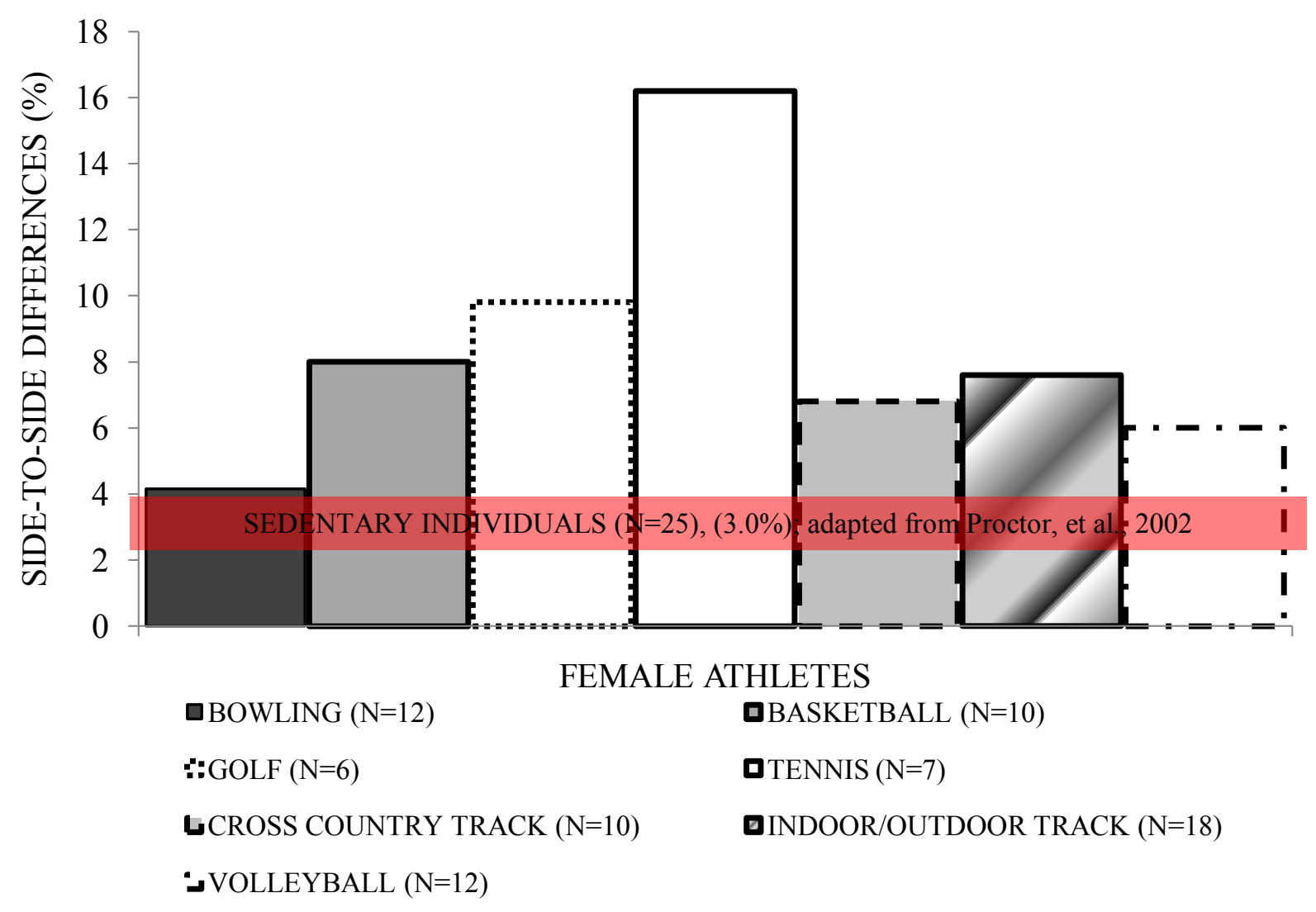

FIGURE 5.2 Comparison of side-to-side arm BMD relative difference between McClanahan, et al., 2002 and Female Bowlers

\subsection{Conclusions}

This pilot study analyzed the side-to-side difference of the bowling arm compared to the non-bowling arm of elite ten-pin collegiate bowlers. From this study, it can be concluded that the female ten-pin bowlers had greater side-to-side forearm BMD difference compared to male bowlers and the control group. Therefore, the type of release of the bowling ball during the delivery phase appears to have an additional effect on the forearm BMD. As observed in the female bowlers that predominantly use more wrist flexion in the release compared to the male bowlers. 


\subsection{Recommendations for Further Research}

This study raised further questions about understanding the effect of bowling on BMD, as well as the need for published peer-reviewed literature on the sport of bowling at all levels. For further research into the effects of bowling on BMD, it would be suggested to investigate more specifically the mechanics of the bowling ball release on forearm BMD. In addition, this author would recommend expanding this study by adding more variables that may or may not be influencing the BMD of the bowling arm, to determine if bowling alone is enough activity to induce an osteogenic effect on bones. Such variables would include analyzing the nutrition of the bowlers. Nutrition is known to have an influence on BMD. Weightlifting regimens would be another variable to look at. It may include a control group of bowlers who only bowl with no supplemental workouts and an experimental group that bowls and includes supplemental workouts. These variables would be tested in a longitudinal study.

Another recommendation would be to expand this type of research on ten-pin bowling and BMD to determine if bowling has an effect on leg and hip BMD. Analyzing BMD of the legs could be used to determine the effect of the slide leg compared to the follow-through leg. Further research on ten-pin bowling and BMD would be beneficial to determine the osteogenic effect of ten-pin bowling on BMD. This could be used to encourage the popularization of the sport of bowling at a younger age when building BMD is most critical. 
BIBLIOGRAPHY 


\section{BIBILIOGRAPHY}

Ahola, R., Korpelainen, R., Vainionpaa, A., Leppaluoto, J., \& Jamsa, T. (2009). Time-course of exercise and its association with 12-month bone changes. BMC musculoskeletal disorders, 10(1), 138. doi: 10.1186/1471-2474-10-138

Akar, S., Sivrikaya, H., Canikli, A., \& Varoglu, E. (2002). Lateralized mineral content and density in distal forearm bones in right-handed men and women: Relation of structure to function. International Journal of Neuroscience, 112(3), 301-311.

Akhter, M. P., Lund, A. D., \& Gairola, C. G. (2005). Bone biomechanical property deterioration due to tobacco smoke exposure. Calcified tissue international, 77(5), 319-326. doi: $10.1007 / \mathrm{s} 00223-005-0072-1$

Alfredson, H., Nordstrom, P., \& Lorentzon, R. (1997). Bone mass in female volleyball players: A comparison of total and regional bone mass in female volleyball players and nonactive females. Calcified tissue international, 60(4), 338-342.

Alfredson, H., Nordstrom, P., Pietila, T., \& Lorentzon, R. (1998). Long-term loading and regional bone mass of the arm in female volleyball players. Calcified tissue international, 62(4), 303-308.

Ali, N., Shonk, C., \& El-Sayed, M. (2009). Bone health in men: Influencing factors. American Journal of Health Behavior, 33(2), 213.

Andreoli, A., Monteleone, M., \& Van Loan, M. (2001). Effects of different sports on bone density and muscle mass in highly trained athletes. Medicine and Science in Sports and Exercise, 33(4), 507-511.

Araujo, A. B., Travison, T. G., Harris, S. S., Holick, M. F., Turner, A. K., \& McKinlay, J. B. (2007). Race/ethnic differences in bone mineral density in men. Osteoporosis International, 18(7), 943-953. doi: 10.1007/s00198-006-0321-9

Ashizawa, N., Nonaka, K., Michikami, S., Mizuki, T., Amagai, H., Tokuyama, K. et al. (1999). Tomographical description of tennis-loaded radius: Reciprocal relation between bone size and volumetric BMD. Journal of Applied Physiology, 86(4), 1347-1351. 
Augestad, L. B., Schei, B., Forsmo, S., Langhammer, A., \& Flanders, W. D. (2004). The association between physical activity and forearm bone mineral density in healthy premenopausal women. Journal of Women's Health (15409996), 13(3), 301-313.

Avdagic, S. C., Baric, I. C., Keser, I., Cecic, I., Satalic, Z., Bobic, J. et al. (2009). Differences in peak bone density between male and female students. Arhiv Za Higijenu Rada I Toksikologiju, 60(1), 79-86. doi: 10.2478/10004-1254-60-2009-1886

Bailey, C., \& Brooke-Wavell, K. (2008). Exercise for optimising peak bone mass in women. The Proceedings of the Nutrition Society, 67, 9.

Bareither, M. L., Grabiner, M. D., \& Troy, K. L. (2008). Habitual site-specific upper extremity loading is associated with increased bone mineral of the ultradistal radius in young women. Journal of Women's Health (15409996), 17(10), 1577-1581.

Bemben, D. A., Buchanan, T. D., Bemben, M. G., \& Knehans, A. W. (2004). Influence of type of mechanical loading, menstrual status, and training season on bone density in young women athletes. Journal of Strength and Conditioning Research, 18(2), 220-226.

Berenson, A. B., Rahman, M., \& Wilkinson, G. (2009). Racial difference in the correlates of bone mineral content/density and age at peak among reproductive-aged women. Osteoporosis International, 20(8), 1439-1449. doi: 10.1007/s00198-008-0817-6

Bianchi, M. L., Baim, S., Bishop, N. J., Gordon, C. M., Hans, D. B., Langman, C. B. et al. (2010). Official positions of the international society for clinical densitometry (iscd) on dxa evaluation in children and adolescents. Pediatric Nephrology, 25(1), 37-47. doi: $10.1007 / \mathrm{s} 00467-009-1249-\mathrm{z}$

Bischoff-Ferrari, H. (2009). Vitamin D: What is an adequate vitamin D level and how much supplementation is necessary? Best Practice \& Research in Clinical Rheumatology, 23(6), 789-795. doi: 10.1016/j.berh.2009.09.005

Bonnick, S. L., Harris, S. T., Kendler, D. L., McClung, M. R., \& Silverman, S. L. (2010). Management of osteoporosis in postmenopausal women: 2010 position statement of the North American Menopause Society. Menopause: Journal of the North American Menopause Society, 17(1), 25-54. doi: 10.1097/gme.0b013e3181e617e6

Boot, A. M., Sluis, M. A., Slobbe, I. M., Krenning, I., Keizer-Schrama, E. P., \& Muinck, S. M. (2010). Peak bone mineral density, lean body mass and fractures. Bone, 46(2), 336-341. doi: 10.1016/j.bone.2009.10.003 
Calbet, J. A. L., Herrera, P. D., \& Rodriguez, L. P. (1999). High bone mineral density in male elite professional volleyball players. Osteoporosis International, 10(6), 468-474.

Capozza, R. F., Cointry, G. R., Cure-RamÃrez, P., Ferretti, J. L., \& Cure-Cure, C. (2004). A DXA study of muscle-bone relationships in the whole body and limbs of 2512 normal men and pre- and post-menopausal women. Bone, 35(1), 283-295. doi:

$10.1016 /$ jbone.2004.03.010

Carey, J. J., Delaney, M. E., Love, T. E., Richmond, B. J., Cromer, B. A., Miller, P. D. et al. (2007). DXA generated z-scores and t-scores may differ substantially and significantly in young adults. Journal of Clinical Densitometry, 10(4), 351-358. doi: 10.1016/j.joed.2007.06.001

Carey, J. J., Delaney, M. F., Love, T. E., Cromer, B. A., Miller, P. D., Richmond, B. J. et al. (2009). Dual-energy x-ray absorptiometry diagnostic discordance between z-scores and tscores in young adults. Journal of Clinical Densitometry, 12(1), 11-16. doi: 10.1016/j.jocd.2008.11.001

Chilibeck, P. D., Davison, K. S., Sale, D. G., Webber, C. E., \& Faulkner, R. A. (2000). Effect of physical activity on bone mineral density assessed by limb dominance across the lifespan. American Journal of Human Biology, 12(5), 633-637.

Cullen, D. M., Smith, R. T., \& Akhter, M. P. (2001). Bone-loading response varies with strain magnitude and cycle number. Journal of Applied Physiology, 91(5), 1971-1976.

Douchi, T., Kuwahata, R., Matsuo, T., Kuwahata, T., Oki, T., Nakae, M. et al. (2004). Agerelated change in the strength of correlation of the lumbar spine bone mineral density with other regions. Maturitas: The European Menopause Journal, 47(1), 55-59.

Dowthwaite, J. N., Flowers, P. P. E., Spadaro, J. A., \& Scerpella, T. A. (2007). Bone geometry, density, and strength indices of the distal radius reflect loading via childhood gymnastic activity. Journal of Clinical Densitometry, 10(1), 65-75. doi: 10.1016/j.jocd.2006.10.003

Ducher, G., Courteix, D., Meme, S., Magni, C., Viala, J. F., \& Benhamou, C. L. (2005). Bone geometry in response to long-term tennis playing and its relationship with muscle volume: A quantitative magnetic resonance imaging study in tennis players. Bone, 37(4), 457-466. doi: 10.1016/j.bone.2005.05.014 
Ducher, G., Prouteau, S., Courteix, D., \& Benhamou, C. L. (2004). Cortical and trabecular bone at the forearm show different adaptation patterns in response to tennis playing. Journal of Clinical Densitometry, 7(4), 399-405.

Ducher, G., Tournaire, N., Meddahi-Pelle, A., Benhamou, C. L., \& Courteix, D. (2006). Shortterm and long-term site-specific effects of tennis playing on trabecular and cortical bone at the distal radius. Journal of bone and mineral metabolism, 24(6), 484-490. doi: 10.1007/s00774-006-0710-3

Duncan, C. S., Blimkie, C. J. R., Cowell, C. T., Burke, S. T., Briody, J. N., \& Howman-Giles, R. (2002). Bone mineral density in adolescent female athletes: Relationship to exercise type and muscle strength. Medicine and Science in Sports and Exercise, 34(2), 286-294.

Elloumi, M., Ben Ounis, O., Courteix, D., Makni, E., Sellami, S., Tabka, Z. et al. (2009). Longterm rugby practice enhances bone mass and metabolism in relation with physical fitness and playing position. Journal of bone and mineral metabolism, 27(6), 713-720. doi: 10.1007/s00774-009-0086-2

Flynn, A. (2003). The role of dietary calcium in bone health. Proceedings of the Nutrition Society, 62(4), 851-858. doi: 10.1079/pns2003301

Fredericson, M., Chew, K., Ngo, J., Cleek, T., Kiratli, J., \& Cobb, K. (2007). Regional bone mineral density in male athletes: A comparison of soccer players, runners and controls. British Journal of Sports Medicine, 41(10), 664-668. doi: 10.1136/bjsm.2006.030783

Frost, H. M. (1997). Why do marathon runners have less bone than weight lifters? A vitalbiomechanical view and explanation. Bone, 20(3), 183-189.

Frost, H. M. (2003). Bone's mechanostat: A 2003 update. Anatomical Record Part A: Discoveries in Molecular Cellular and Evolutionary Biology, 275A(2), 1081-1101. doi: 10.1002/ar.a.10119

Fuerst, T., Gluer, C. C., \& Genant, H. K. (1995). Performance evaluation of a new bone densitometer - Hologic QDR-4500. Journal of Bone and Mineral Research, 10, S370S370.

Ginty, F., Rennie, K. L., Mills, L., Stear, S., Jones, S., \& Prentice, A. (2005). Positive, sitespecific associations between bone mineral status, fitness, and time spent at high-impact activities in 16-to 18-year-old boys. Bone, 36(1), 101-110. doi:

10.1016/j.bone.2004.10.001 
Griffith, J. F., \& Genant, H. K. (2008). Bone mass and architecture determination: State of the art. Best Practice \& Research Clinical Endocrinology \& Metabolism, 22(5), 737-764. doi: 10.1016/j.beem.2008.07.003

Guadalupe-Grau, A., Fuentes, T., Guerra, B., \& Calbet, J. A. L. (2009). Exercise and bone mass in adults. Sports Medicine, 39(6), 439-468.

Hamdy, R. C., Anderson, J. S., Whalen, K. E., \& Harvill, L. M. (1994). Regional differences in bone-density of young men involved in different exercises. Medicine and Science in Sports and Exercise, 26(7), 884-888.

Helge, E. W., \& Kanstrup, I. L. (2002). Bone density in female elite gymnasts: Impact of muscle strength and sex hormones. Medicine and Science in Sports and Exercise, 34(1), 174-180.

Hogstrom, M., Nordstrom, A., Alfredson, H., Lorentzon, R., Thorsen, K., \& Nordstrom, P. (2007). Current physical activity is related to bone mineral density in males but not in females. International Journal of Sports Medicine, 28(5), 431-436. doi: 10.1055/s-2006924514

Holmberg, A., Johnell, O., Akesson, K., Nilsson, P., Nilsson, J.-A., \& Berglund, G. (2004). Forearm bone mineral density in 1294 middle-aged women: A strong predictor of fragility fractures. Journal of Clinical Densitometry, 7(4), 419-423.

Holroyd, C., Cooper, C., \& Dennison, E. (2008). Epidemiology of osteoporosis. Best Practice \& Research Clinical Endocrinology \& Metabolism, 22(5), 671-685. doi: 10.1016/j.beem.2008.06.001

Huang, T. H., Hsieh, S. S., Liu, S. H., Chang, F. L., Lin, S. C., \& Yang, R. S. (2010). Swimming training increases the post-yield energy of bone in young male rats. Calcified tissue international, 86(2), 142-153. doi: 10.1007/s00223-009-9320-0

Isaksson, H., Tolvanen, V., Finnilä, M., Iivarinen, J., Tuukkanen, J., Seppänen, K. et al. (2009). Physical exercise improves properties of bone and its collagen network in growing and maturing mice. Calcified tissue international, 85(3), 247-256.

Iwamoto, J., Sato, Y., Takeda, T., \& Matsumoto, H. (2009). Role of sport and exercise in the maintenance of female bone health. Journal of bone and mineral metabolism, 27(5), 530537. doi: 10.1007/s00774-009-0066-6 
Jovcevska, J. M., Stratrova, S. S., Gjorgovski, I., Gruev, T., Kotevska, M. N., JanicevicIvanovska, D. et al. (2009). Bone turnover markers relations to postmenopausal osteoporosis. Journal of Medical Biochemistry, 28(3), 161-165. doi: 10.2478/v10011009-0012-0

Jurimae, J., Purge, P., Jurimae, T., \& von Duvillard, S. P. (2006). Bone metabolism in elite male rowers: Adaptation to volume-extended training. European journal of applied physiology, 97(1), 127-132. doi: 10.1007/s00421-006-0158-0

Juzwiak, C. R., Amancio, O. M. S., Vitalle, M. S. S., Szejnfeld, V. L. c., \& Pinheiro, M. M. (2008). Effect of calcium intake, tennis playing, and body composition on bone-mineral density of brazilian male adolescents. International Journal of Sport Nutrition \& Exercise Metabolism, 18(5), 524-538.

Karlsson, M. (2004). Review has exercise an antifracture efficacy in women? Scandinavian Journal of Medicine \& Science in Sports, 14(1), 2-15.

Karsdal, M. A., Qvist, P., Christiansen, C., \& Tanko, L. B. (2006). Optimising antiresorptive therapies in postmenopausal women - why do we need to give due consideration to the degree of suppression? Drugs, 66(15), 1909-1918.

Kemmler, W., Engelke, K., Baumann, H., Beeskow, C., von Stengel, S., Weineck, J. et al. (2006). Bone status in elite male runners. European journal of applied physiology, 96(1), 78-85. doi: 10.1007/s00421-005-0060-1

Kerschan-Schindl, K., Thalmann, M., Sodeck, G. H., Skenderi, K., Matalas, A. L., Grampp, S. et al. (2009). A 246-km continuous running race causes significant changes in bone metabolism. Bone, 45(6), 1079-1083. doi: 10.1016/j.bone.2009.07.088

Kohrt, Barry, D. W., \& Schwartz, R. S. (2009). Muscle forces or gravity: What predominates mechanical loading on bone? Medicine and Science in Sports and Exercise, 41(11), 20502055.

Kohrt, Bloomfield, S. A., Little, K. D., Nelson, M. E., \& Yingling, V. R. (2004). Physical activity and bone health: American College of Sports Medicine position stand. Medicine and Science in Sports and Exercise, 36(11), 1985-1996. doi: 10.1249/01.mss.0000142662.21767.58

Krall, E. A., \& Dawson-Hughes, B. (1993). Heritable and life-style determinants of bone mineral density. Journal of Bone and Mineral Research, 8(1), 1-9. 
Lang, D. H., Conroy, D. E., Lionikas, A., Mack, H. A., Larsson, L., Vogler, G. P. et al. (2009). Bone, muscle, and physical activity: Structural equation modeling of relationships and genetic influence with age. Journal of Bone and Mineral Research, 24(9), 1608-1617. doi: 10.1359/JBMR.090418

Lapauw, B. M., Taes, Y., Bogaert, V., Vanbillemont, G., Goemaere, S., Zmierczak, H. G. et al. (2009). Serum estradiol is associated with volumetric BMD and modulates the impact of physical activity on bone size at the age of peak bone mass: A study in healthy male siblings. Journal of Bone and Mineral Research, 24(6), 1075-1085. doi:

$10.1359 / \mathrm{jbmr} .081260$

Leslie, W. D., Tsang, J. F., Caetano, P. A., \& Lix, L. M. (2007). Effectiveness of bone mineral density measurement for predicting osteoporotic fractures in clinical practice. The Journal of Clinical Endocrinology \& Metabolism, 92(1), 77-81. doi: 10.1210/jc.20061415

Lester, M. E., Urso, M. L., Evans, R. K., Pierce, J. R., Spiering, B. A., Maresh, C. M. et al. (2009). Influence of exercise mode and osteogenic index on bone biomarker responses during short-term physical training. Bone, 45(4), 768-776. doi:

10.1016/j.bone.2009.06.001

Libuda, L., Alexy, U., Remer, T., Stehle, P., Schoenau, E., \& Kersting, M. (2008). Association between long-term consumption of soft drinks and variables of bone modeling and remodeling in a sample of healthy german children and adolescents. American Journal of Clinical Nutrition, 88(6), 1670-1677. doi: 10.3945/ajcn.2008.26414

Lloyd, T., Eggli, D. F., Miller, K. L., Eggli, K. D., \& Dodson, W. C. (1998). Radiation dose from DXA scanning to reproductive tissues of females. Journal of Clinical Densitometry, 1(4), 379-383.

Lohman, M., Tallroth, K., Kettunen, J. A., \& Marttinen, M. T. (2009). Reproducibility of dualenergy x-ray absorptiometry total and regional body composition measurements using different scanning positions and definitions of regions. Metabolism-Clinical and Experimental, 58(11), 1663-1668. doi: 10.1016/j.metabol.2009.05.023

Maimoun, L., Manetta, J., Couret, I., Dupuy, A. M., Mariano-Goulart, D., Micallef, J. P. et al. (2006). The intensity level of physical exercise and the bone metabolism response. International Journal of Sports Medicine, 27(2), 105-111. doi: 10.1055/s-2005-837621 
Matsumoto, T., Nakagawa, S., Nishida, S., \& Hirota, R. (1997). Bone density and bone metabolic markers in active collegiate athletes: Findings in long-distance runners, judoists, and swimmers. International Journal of Sports Medicine, 18(6), 408-412.

McClanahan, B. S., Harmon-Clayton, K., Ward, K. D., Klesges, R. C., Vukadinovich, C. M., \& Cantler, E. D. (2002). Side-to-side comparisons of bone mineral density in upper and lower limbs of collegiate athletes. Journal of Strength and Conditioning Research, 16(4), 586-590.

Medelli, J., Lounana, J., Menuet, J., Shabani, M., \& Cordero-MacIntyre, Z. (2009). Is osteopenia a health risk in professional cyclists? Journal of Clinical Densitometry, 12(1), 28-34. doi: 10.1016/j.jocd.2008.07.057

Medelli, J., Shabani, M., Lounana, J., Fardellone, P., \& Campion, F. (2009). Low bone mineral density and calcium intake in elite cyclists. Journal of Sports Medicine and Physical Fitness, 49(1), 44.

Mihaljevic, I., Mudri, D., Smolic, R., Smolic, M., \& Tucak-Zoric, S. (2009). Biochemical bone turnover markers: Significance in patients with osteoporosis. Collegium Antropologicum, $33,21-24$.

Morel, J., Combe, B., Francisco, J., \& Bernard, J. (2001). Bone mineral density of 704 amateur sportsmen involved in different physical activities. Osteoporosis International, 12(2), $152-157$.

Mudd, L. M., Fornetti, W., \& Pivarnik, J. M. (2007). Bone mineral density in collegiate female athletes: Comparisons among sports. Journal of Athletic Training, 42(3), 403-408.

Mullen, M. (2004). Bowling fundamentals: A better way to learn the basics. Champaign: Human Kinetics.

Neil, J. M., \& Schweitzer, M. E. (2008). Humeral cortical and trabecular changes in the throwing athlete: A quantitative computed tomography study of male college baseball players. Journal of Computer Assisted Tomography, 32(3), 492-496.

Nevill, A. M., Holder, R. L., \& Stewart, A. D. (2004). Do sporting activities convey benefits to bone mass throughout the skeleton? Journal of Sports Sciences, 22(7), 645-650. 
Nichols, D. L., Sanborn, C. F., \& Essery, E. V. (2007). Bone density and young athletic women: An update. Sports Medicine, 37(11), 1001(1014).

Nikander, R., Sievanen, H., Heinonen, A., \& Kannus, P. (2005). Femoral neck structure in adult female athletes subjected to different loading modalities. Journal of Bone and Mineral Research, 20(3), 520-528. doi: 10.1359/jbmr.041119

Nikander, R., Sievanen, H., Heinonen, A., Karstila, T., \& Kannus, P. (2008). Load-specific differences in the structure of femoral neck and tibia between world-class moguls skiers and slalom skiers. Scandinavian Journal of Medicine \& Science in Sports, 18(2), 145 153.

Nikander, R., Sievanen, H., Uusi-Rasi, K., Heinonen, A., \& Kannus, P. (2006). Loading modalities and bone structures at nonweight-bearing upper extremity and weight-bearing lower extremity: A pQCT study of adult female athletes. Bone, 39(4), 886-894. doi: 10.1016/j.bone.2006.04.005

Orwoll, E. S., Belknap, J. K., \& Klein, R. F. (2001). Gender specificity in the genetic determinants of peak bone mass. Journal of Bone and Mineral Research, 16(11), 19621971.

Ozdurak, R. H., Duz, S., Arsal, G., Akinci, Y., Kablan, N., Isikli, S. et al. (2003). Quantitative forearm muscle strength influences radial bone mineral density in osteoporotic and healthy males. Technology and Healthcare, 11, 253-261.

Papachroni, K. K., Karatzas, D. N., Papavassiliou, K. A., Basdra, E. K., \& Papavassiliou, A. G. (2009). Mechanotransduction in osteoblast regulation and bone disease. Trends in Molecular Medicine, 15(5), 208-216. doi: 10.1016/j.molmed.2009.03.001

Patel, R., Blake, G. M., \& Fogelman, I. (2007). Peripheral and central measurements of bone mineral density are equally strongly associated with clinical risk factors for osteoporosis. Calcified tissue international, 80, 89.

Pearson, O. M., \& Lieberman, D. E. (2004). The aging of Wolff's "law": ontogeny and responses to mechanical loading in cortical bone. Yearbook of Physical Anthropology, 47, 68-99.

Pettersson, U., Alfredson, H., Nordstrom, P., Henriksson-Larsen, K., \& Lorentzon, R. (2000). Bone mass in female cross-country skiers: Relationship between muscle strength and different BMD sites. Calcified tissue international, 67(3), 199-206. 
Pikkarainen, E., Lehtonen-Veromaa, M., Kautiainen, H., Heinonen, O. J., Viikari, J., \& Möttönen, T. (2009). Exercise-induced training effects on bone mineral content: A 7-year follow-up study with adolescent female gymnasts and runners. Scandinavian Journal of Medicine \& Science in Sports, 19(2), 166-173.

Proctor, K. L., Adams, W. C., Shaffrath, J. D., \& Van Loan, M. D. (2002). Upper-limb bone mineral density of female collegiate gymnasts versus controls. Medicine and Science in Sports and Exercise, 34(11), 1830-1835. doi: 10.1249/01.mss.0000037094.71541.b9

Proff, P., \& Romer, P. (2009). The molecular mechanism behind bone remodeling: A review. Clinical Oral Investigations, 13(4), 355-362. doi: 10.1007/s00784-009-0268-2

Rautava, E., Lehtonen-Veromaa, M., Kautiainen, H., Kajander, S., Heinonen, O. J., Viikari, J. et al. (2007). The reduction of physical activity reflects on the bone mass among young females: A follow-up study of 142 adolescent girls. Osteoporosis International, 18, 915.

Rector, R. S., Rogers, R., Ruebel, M., Widzer, M. O., \& Hinton, P. S. (2009). Lean body mass and weight-bearing activity in the prediction of bone mineral density in physically active men. Journal of Strength and Conditioning Research, 23(2), 427-435. doi: 10.1519/JSC.0b013e31819420e1

Rico, H., Gonzalezriola, J., Revilla, M., Villa, L. F., Gomezcastresana, F., \& Escribano, J. (1994). Cortical versus trabecular bone mass - influence of activity on both bone components. Calcified tissue international, 54(6), 470-472.

Rizzoli, R. (2008). Nutrition: Its role in bone health. Best Practice \& Research Clinical Endocrinology \& Metabolism, 22(5), 813-829. doi: 10.1016/j.beem.2008.08.005

Sanchis-Moysi, J., Dorado, C., Vicente-Rodriguez, G., Milutinovic, L., Garces, G. L., \& Calbet, J. A. L. (2004). Inter-arm asymmetry in bone mineral content and bone area in postmenopausal recreational tennis players. Maturitas, 48(3), 289-298. doi: 10.1016/j.maturitas.2004.03.008

Sanders, K. M., Nowson, C. A., Kotowicz, M. A., Briffa, K., Devine, A., \& Reid, I. R. (2009). Calcium and bone health: Position statement for the Australian and New Zealand Bone and Mineral Society, osteoporosis Australia and the Endocrine Society of Australia. Medical Journal of Australia, 190(6), 316-320. 
Sergi, G., Perissinotto, E., Zucchetto, M., Enzi, G., Manzato, E., Giannini, S. et al. (2009). Upper limb bone mineral density and body composition measured by peripheral quantitative computed tomography in right-handed adults: The role of the dominance effect. Journal of endocrinological investigation, 32(4), 298-302.

Shaw, C. N., \& Stock, J. T. (2009). Habitual throwing and swimming correspond with upper limb diaphyseal strength and shape in modern human athletes. American Journal of Physical Anthropology, 140(1), 160-172.

Shepherd, J. A., \& Lu, Y. (2007). A generalized least significant change for individuals measured on different DXA systems. Journal of Clinical Densitometry, 10(3), 249-258. doi: $10.1016 /$ j.jocd.2007.05.002

Shocker Bowling. (2009, August 11). Shocker bowling program fact sheet Retrieved March 30, 2010, from http://webs.wichita.edu

Smock, A. J., Hughes, J. M., \& Popp, K. L. (2009). Bone volumetric density, geometry, and strength in female and male collegiate runners. Medicine and Science in Sports and Exercise, 41(11), 2026-2032.

Sweet, M. G., Sweet, J. M., Jeremiah, M. P., \& Galazka, S. S. (2009). Diagnosis and treatment of osteoporosis. American family physician, 79(3), 193-200.

TenpinBowling.org. (2003-2006). The game: history. All About Bowling Retrieved April 25, 2010, from http://www.tenpinbowling.org/view.php?page=the game.history

Tervo, T., Nordstrom, P., Neovius, M., \& Nordstrom, A. (2009). Reduced physical activity corresponds with greater bone loss at the trabecular than the cortical bone sites in men. Bone, 45(6), 1073-1078. doi: 10.1016/j.bone.2009.07.007

Turner, C. H. (2000). Exercise the skeleton: Beneficial effects of mechanical loading on bone structure. Endocrinologist, 10(3), 164-169.

United States Bowling Congress. (2006). Silver Certification: Coaching the physical game USBC Coaching (pp. 1-52). Arlington.

United States Bowling Congress. (2008). Level 1 coaching: Physical game development USBC Coaching (pp. 1-42). Arlington. 
United States Bowling Congress. (2009). Bronze certification: Physical game USBC Coaching (pp. 1-54). Arlington.

Vainionpää, A., Korpelainen, R., Väänänen, H., Haapalahti, J., Jämsä, T., \& Leppäluoto, J. (2009). Effect of impact exercise on bone metabolism. Osteoporosis International, 20, 1725.

Vicente-Rodriguez, G., Dorado, C., Perez-Gomez, J., Gonzalez-Henriquez, J. J., \& Calbet, J. A. L. (2004). Enhanced bone mass and physical fitness in young female handball players. Bone, 35(5), 1208-1215. doi: 10.1016/j.bone.2004.06.012

Vicente-Rodriguez, G., Ezquerra, J., Mesana, M. I., Fernandez-Alvira, J. M., Rey-Lopez, J. P., Casajus, J. A. et al. (2008). Independent and combined effect of nutrition and exercise on bone mass development. Journal of bone and mineral metabolism, 26(5), 416-424. doi: $10.1007 / \mathrm{s} 00774-007-0846-9$

Walters, J., Koo, W. W. K., Bush, A., \& Hammami, M. (1998). Effect of hand dominance on bone mass measurement in sedentary individuals. Journal of Clinical Densitometry, 1(4), 359-367.

Warden, S. J., Bogenschutz, E. D., Smith, H. D., \& Gutierrez, A. R. (2009). Throwing induces substantial torsional adaptation within the midshaft humerus of male baseball players. Bone, 45(5), 931-941. doi: 10.1016/j.bone.2009.07.075

Weaver, C. M. (2000). Calcium requirements of physically active people. American Journal of Clinical Nutrition, 72(2), 579S-584S.

Whittington, J., Schoen, E., Labounty, L. L., Hamdy, R., Ramsey, M. W., Stone, M. E. et al. (2009). Bone mineral density and content of collegiate throwers: Influence of maximum strength. Journal of Sports Medicine and Physical Fitness, 49(4), 464-473.

Wilks, D. C., Gilliver, S. F., \& Rittweger, J. (2009). Forearm and tibial bone measures of distance- and sprint-trained master cyclists. Medicine and Science in Sports and Exercise, $41(3), 566-573$.

Wilsgaard, T., Emaus, N., Ahmed, L. A., Grimnes, G., Joakimsen, R. M., Omsland, T. K. et al. (2009). Lifestyle impact on lifetime bone loss in women and men. American Journal of Epidemiology, 169(7), 877-886. doi: 10.1093/aje/kwn407 
Zhou, Y., Zhu, Z. L., Guan, X. X., Hou, W. W., \& Yu, H. Y. (2009). Reciprocal roles between caffeine and estrogen on bone via differently regulating camp/pka pathway: The possible mechanism for caffeine-induced osteoporosis in women and estrogen's antagonistic effects. Medical Hypotheses, 73(1), 83-85. doi: 10.1016/j.mehy.2009.01.029

Zofková, I. (2008). Hormonal aspects of the muscle-bone unit. Physiological Research, 57, S159. 
APPENDIX 


\title{
APPENDIX A
}

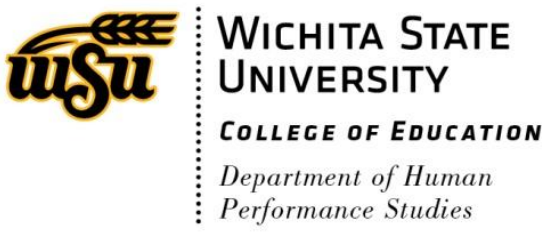

\section{ASSESSMENT OF BONE DENSITY AND MUSCULAR STRENGTH IN THE DOMINANT AND NON-DOMINANT ARMS OF ELITE COLLEGE BOWLERS}

\author{
Informed Consent Form
}

PURPOSE: You are being invited to participate in a research study that will assess bone health and muscular strength in college bowlers. This research study will be conducted at Wichita State University by Dr. Jeremy Patterson and Graduate Research Students Bryce Winklepleck and Ashley Fryman. Approximately 24 members of the WSU Bowling Team will be enrolled.

Strength training has been shown to have a positive influence on athletic performance in many different sports and has been shown to increase bone mineral density. However, there are very few studies assessing bowlers and your sport presents unique mechanics (highly repetitive single arm swings with weight) that may result in an increased bone density in your bowling arm. Additionally, we will perform follow-up testing to assess the effects of the Bowling Team strength training program that you will participate in throughout the season.

You do not have to participate in this research study. It is important that before you make a decision to participate, you read the rest of this form. You should ask as many questions as needed to understand what will happen to you if you participate in this study.

PROCEDURES: If you decide to participate in this study, you will be asked to sign this consent form that allows us to gather information from you and perform the bone scan and strength test described below. A full-body DXA unit (Hologic QDR 4500) will be used to quantify muscle, fat, bone mineral content, and bone mineral density of the whole body and forearm. You will lie down on the bed of the scan machine (DXA) for approximately 8 minutes while the scan arm passes over you several times taking images of your bones. Testing will occur in the Human Performance Laboratory at Wichita State University. All participants will begin with their height and body weight measurement. Due to the low radiation dose all female participants will be administered a pregnancy test. In the event of a positive test that participant will not be allowed to participate in the study. The upper body strength tests will also be completed in the Human Performance Laboratory, using both the dominant and non-dominant arm. An assessment device called an isokenetic dynameter will be used to measure your muscular strength and muscular endurance. You will perform a pushing and pulling motion that will allow the arm to be extened and retracted. The second set of exercises will include a fast paced motion with a high repetion count (20), which will test muscle endurance. There will be four sets of individual exercises ( 2 practice sets and 2 test sets) and between each set a 30-60 second rest will accure. This modified exercise will assess the strength and endurance of your muscles surrounding the shoulder joint.

Total testing time will take approximately 30 minutes to complete. 


\section{APPENDIX A (continued)}

DISCOMFORT/RISKS: There exists the possibility of certain changes that may occur during the DXA assessment. The parts of your body that will receive the most radiation exposure are the skin, although your whole body will be exposed to radiation. The radiation exposure is small compared with other commonly accepted medical procedures such as chest x-rays, lumbar spine x-rays, and dental bite wings. In fact, patient dose is even smaller than exposure to natural background radiation. The amount of radiation that you will receive from this procedure is equivalent to a uniform whole-body exposure of 0.1 mrem, with the exposure being 2.4-4.8 mrem per hip (femur) and spine scan. The typical radiation exposure from a normal chest x-ray is $30 \mathrm{mrem}$. Although you will have a small amount of exposure, the risk from radiation exposure of this magnitude is too small to be measured directly and is considered to be negligible when compared with other everyday risk. We also want to make sure that the amount of radiation that you have received in the past year is within safe limits, so if you have had an x-ray, let us know. If you have recently undergone CT (Computerized Tomography), PET, fluoroscopic, or nuclear medicine studies within the past year, you cannot obtain DXA assessment. If you are currently pregnant, or receive a positive pregnancy test prior to assessment, you cannot obtain a DXA assessment. Other changes during DXA assessment may include but are not limited to motion sickness (lightheadedness, nausea) due to the mechanical movement of the DXA machine or muscle discomfort due to body position. The Radiation Safety Officer (Dr. Glendon Miller, 978-3347) of Wichita State University can provide you with more information about radiation exposure if you are interested.

The muscular strength test is an exercise test, and you may experience fatigue, muscle soreness, dizziness, and/or shortness of breath. Signs and symptoms for stopping the strength and endurance tests include: anginal pain, marked dyspnea, apprehension, mental confusion or lack of co-ordination, facial pallor or sweating. Any time during the test, you can stop the test. The testing will be conducted under direct supervision of research personnel, who will instruct you on exercise technique. A warm-up before testing and a cool-down following will also be directed to reduce the chances of injury or discomfort.

In the unlikely event of a medical emergency, staff will be trained to respond appropriately. Procedures for the notification of Emergency Medical Services will be formalized in writing and these procedures will be practiced by the research personnel

BENEFITS: The DXA assessment will provide information pertaining to your bone mineral content, bone mineral density and body composition. The information received is not intended to diagnose osteopenia, osteoporosis, and/or obesity. It is suggested that you share the information obtained from you DXA assessment with your primary care physician if you are concerned with your results. You will be given an additional copy of all assessment information for this purpose. The strength testing will be beneficial for you and your coach to assess the in-season strength training program that is part of your overall team conditioning.

The information gained in this study will be particularly beneficial to exercise professionals, medical professionals, and the bowling community. This is an original study that has the potential to report an outcome that would be very beneficial to the general public and have a significant contribution to the scientific field.

CONFIDENTIALITY: Any information obtained in this study in which you can be identified will remain confidential and will be disclosed only with your permission.

COMPENSATION OR TREATMENT: Wichita State University does not provide medical treatment or other forms of reimbursement to persons injured as a result of or in connection with participation in research activities conducted by Wichita State University or its faculty, staff, or students. If you believe that you have been injured as a result of participating in the research covered by this consent form, you can contact the 


\section{APPENDIX A (continued)}

Office of Research Administration, Wichita State University, Wichita, KS 67260-0007, telephone (316) 9783285 .

REFUSAL/WITHDRAWAL: Participation in this study is entirely voluntary. Your decision whether or not to participate will not affect your future relations with Wichita State University. If you agree to participate in this study, you are free to withdraw from the study at any time without penalty.

CONTACT: If you have any questions about this research, you can contact me: Dr. Jeremy A. Patterson, office \#112, Heskett Center, telephone (316) 978-5440. If you have questions pertaining to your rights as a research subject, or about research-related injury, you can contact the Office of Research Administration at Wichita State University, Wichita, KS 67260-0007, telephone (316) 978-3285.

You are under no obligation to participate in this study. Your signature indicates that you have read the information provided above and have voluntarily decided to participate. You will be given a copy of this consent form to keep.

Signature of Subject

Witness Signature
Date

Date 


\section{APPENDIX B \\ IRB No. \\ Expedited? \\ Reviewer's Initials \\ Date to Reviewer \\ Wichita State University Institutional Review Board (IRB) for the Protection of Human Subjects}

\section{Application for Approval of Research Involving Human Subjects}

Double click gray boxes to enter information. Please check spelling, punctuation, and grammar before submitting.

Name of Principal Investigator(s): Jeremy Patterson

(For a student project, Principal Investigator must be a WSU faculty member; student is listed as Co-Investigator.)

Departmental/Program Affiliation of PI: ___ $\frac{5440}{\text { E-mail _ jeremy.patterson@wichita.edu }}$

Name(s) of Co-Investigator(s): _Bryce Winklepleck and Ashley Fryman

Co-Investigator(s) is/are: Undergraduate Student

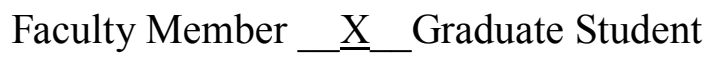

Other, please specify

Type of Project: __ Class Project __ Capstone Project _ Thesis or Dissertation

Funded Research _ _ X Unfunded Research _ _ Secondary Data Collection/Analysis Program Evaluation

If student project, address of student: $\quad \underline{2710 \mathrm{~N} \text {. Glendale }}$

Title of Project/Proposal: ___ Assessment of bone density and muscular strength in the dominant and non-dominant arms of elite college bowlers

Expected Completion Date:__ July 2010_ Funding Agency (if applicable):

Please attach additional sheets, if necessary, with numbers of responses corresponding to those listed below.

1. Describe the research in non-technical language. 


\section{APPENDIX B (continued)}

The proposed study, is a unique assessment of an elite category of athletes that are significantly under represented in the exercise science/sports medicine literature. This study will assess the effects of bowling and strength training on the dominant and non-dominant arms of college bowlers. Strength training has a direct effect on athletic performance in many different sports and has been shown to increase bone mineral density. There is minimal research proving the effects of this type of conditioning on bowling performance. The WSU Bowling Team won National Titles for Men"es and Women "es Teams in 2009 and are the top ranked program in the country. Each member of the team practices daily with 100-300 repetitions (shots) of the same movement with a heavy weight that is bared onto a single arm. Thus, the mechanics of the sport at this elite level may result in physiological and anatomical adaptations, these may be able to be assessed through the initial assessment (baseline). Additionally, the WSU Bowling Team has a strength and conditioning program in place for the duration of their upcoming season, and effects of the training can be assessed through follow-up testing (endpoint). The purpose of this study is to gain knowledge of body composition, bone density, and strength within the dominant and nondominant arms before and after a bowling season, and correlate the results with bowling performance.

2. Describe the benefits of the research to the human subjects, if any, and of the benefits to human or scientific knowledge.

Participants in this study will benefit from greater knowledge and understanding of their overall health through assessments of their body compositions and muscular strength and endurance.

The information obtained from this study will be of benefit to exercise professionals and the bowling community. This study has the potential to report an outcome that would be beneficial to the general public and have a significant contribution to the scientific body of knowledge. Of particular interest is bone mineral density levels in their bowling arm compared to the nonbowling arm.

3. Describe the subjects, how the subjects are to be selected, how many are to be used, and indicate explicitly whether any are minors (under age 18 per Kansas law) or otherwise members of "vulnerable" populations, including, but not limited to, pregnant women, prisoners, psychiatric patients, etc.

24 subjects (12 male; 12 female) from the WSU Bowling team will be recruited under the direction of Jeremy Patterson and Bryce Winklepleck on a volunteer basis to participate in this study. All members of the WSU Bowling team are over the age of 18 years. Each particapant will sign a consent form approved by WSU IRB. Participants in the study will have made the final team cut and are members of the Bowling, ,A $\mathrm{A}^{\mathrm{ee}}$ Team. Current health status of the participant has been predetermined by mandatory team physical exams by a licensed practitioner and deemed physically fit. 


\section{APPENDIX B (continued)}

4. Describe each procedure step-by-step, including the frequency, duration, and location of each procedure.

Volunteer participants will complete an informed consent form approved by both the WSU IRB and by the WSU Bowling Team Head Coach prior to the commencement of the study. Assessments of body composition, with a dual energy x-ray absorptiometry (DXA) system, and muscular strength and endurance through the use of isokinetic dynamometry will be conducted prior to the start of the bowling season (baseline; Oct-Nov) and at the conclusion of the bowling season (endpoint; Apr-May).

\section{Bone Densitometry Test (DXA)}

Participants will undergo one bone densitometry test and this will be completed in the Human Performance Lab (214 Heskett Center) at WSU. A full-body DXA unit (Hologic QDR 4500) will be used to quantify muscle, fat, bone mineral content, and bone mineral density of the whole body. The participant will also be measured for height and body weight. Due to the low X-ray emission of the DXA machine, as a precautionary measure the pre-menopausal female participants will be administered a pregnancy test. In the event of a positive test, the participant will not be allowed to continue with the study. The participants will then be scanned using the full body and forearm mode. The estimated test time is 10 minutes per scan.

\section{Isokinetic Dynamometry}

Bilateral skeletal muscle strength and endurance for elbow extension / flexion will be assessed using an isokinetic dynamometer (BIODEX ${ }^{\circledR}$; System 4 Pro, New York, NY, USA) with microprocessor, which will be calibrated for torque and angular velocity according to manufacturer protocols. Limb position and a torque correction for limb weight are calibrated prior to each movement pattern. Limb and torso alignments and machine settings will be recorded at the time of baseline and replicated for endpoint. Full range of movement within the constraints of the equipment was prescribed for each movement pattern in order to eliminate errors that could be caused by participants who failed to complete full repetitions. Standard instructions will be issued with regard to both the technique and the maximal effort required during each test. The patients then practice the movement patterns just prior to each trial. If smooth curves for torque are not obtained during practice, they are required to repeat these after a brief rest. Strength of the elbow extensors and flexors are measured as the peak angular force (torque, $\mathrm{Nm}$ ) generated during three maximal continuous repetitions at $60^{\circ} \cdot \mathrm{sec}^{-1}$ angular velocity. Following two minutes of rest, endurance is determined as the total angular work (joules) achieved during the middle 16 of 20 consecutive maximal repetitions at $240^{\circ} \cdot \mathrm{sec}^{-1}$. A recovery period of two minutes was allowed between each of the two (ie. elbow strength and elbow endurance) maneuvers

5. Describe any risks or discomforts (physical, psychological, or social) and how they will be minimized. 


\section{APPENDIX B (continued)}

Bone Densitometry Test (DEXA): The Hologic QDR 4500 system uses a low level of x-rays with two different energies to measure fat and lean tissue. Due to the low level of $\mathrm{x}$-rays, each female participant will be administered a pregnancy test. In the full body mode used in this study, it also estimate bone mineral content and bone mineral density. Technique factors for the QDR 4500 are determined automatically for each type of scan and cannot be altered by the operator. The devices emit low radiation doses and present minimal exposure to both patient and the operator. Use of this equipment for research purposes has been previously approved by the Kansas Department of Health and Environment and the WSU IRB.

Signs and symptoms for stopping the strength and endurance tests include: anginal pain, marked dyspnea, apprehension, mental confusion or lack of co-ordination, facial pallor or sweating. Considering this is an exercise test, participants may experience fatigue, muscle soreness, and shortness of breath. Any time during the test, the participant can stop the test.The isokinetic dynomometer testing will be conducted in the Human Performance Laboratory (214 Heskett Center) under direct supervision of research personnel. Personnel supervising the test will have Professional Rescuer Certification with direct acess to an AED and emergency phone for futher medical attention.

All particapants will complete an informed consent approved by WSU IRB.

Proper technique will be taught for testing, emphasizing warm-up, exercise test, and cool-down.

Research personnel will be present during testing and research personnel will be trained to recognize signs of exercise intolerance.

In the unlikely event of a medical emergency, staff will be trained to respond appropriately. Procedures for the notification of Emergency Medical Services will be formalized in writing and these procedures will be practiced by the research personnel.

6. Would subjects undergo these or similar procedures (medical, psychological, educational, etc.) if they were not taking part in this research? _ Yes _ $\underline{X}$ _ No

7. Describe how the subject"s personal privacy is to be protected and confidentiality of information guaranteed (e.g. disposition of questionnaires, interview notes, recorded audio or videotapes, etc.).

The protocols will have been approved by The Wichita State University Institutional Review Board. Any time during the study the participant may withdraw their consent to participate without prejudice towards them. Such withdrawal can be for any reason the individual chooses.

The results of the study will be kept absolutely confidential. Results will be combined with other participants so it will not be possible to identify personal data in a published report; identifying characteristics (e.g., names) will not be directly associated with any of the results. Electronic data will by stored on a password protected desktop computer and any hard copies of data will be 


\section{APPENDIX B (continued)}

stored in a locked filing cabinet and maintain all standards of security set forth by HIPPA regulations.

8. Describe the informed consent process and attach a copy of all consent and/or assent documents. These documents must be retained for three years beyond completion of the study. Any waiver of written informed consent must be justified.

An informed consent document is justified due to the participant population and the type of testing involved. Current health status of the participant has been predetermined by mandatory team physical exams by a licensed practitioner and deemed physically fit. The participant will be fully briefed prior to the study on all procedures to be used and any discomfort that may be expected. The participant will be given the opportunity to ask questions regarding the consent form. The principal investigator, co-investigator and the participants will be available to answer these questions verbally.

Informed consent will be obtained prior to the commencement of the study. The participant will read and sign an Informed Consent Form approved by the WSU IRB.

9. Attach all supporting material, including, but not limited to, questionnaire or survey forms and letters of approval from cooperating institutions.

The Principal Investigator agrees to abide by the federal regulations for the protection of human subjects and to retain consent forms for a minimum of three (3) years beyond the completion of the study. If the data collection or testing of subjects is to be performed by student assistants, the Principal Investigator will assume full responsibility for supervising the students to ensure that human subjects are adequately protected.

Signature of Principal Investigator

Date

Signature of Co-Investigator

Date 